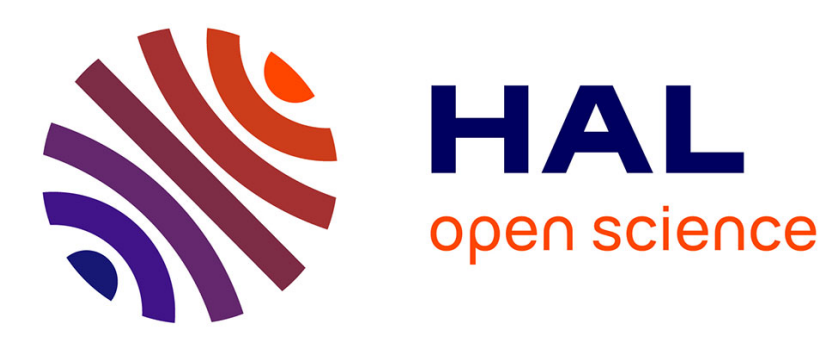

\title{
Constraining the anisotropy structure of the crust by joint inversion of seismic reflection travel times and wave polarizations
}

\author{
Jingyi Chen, Jiwen Teng, José Badal
}

\section{- To cite this version:}

Jingyi Chen, Jiwen Teng, José Badal. Constraining the anisotropy structure of the crust by joint inversion of seismic reflection travel times and wave polarizations. Journal of Seismology, 2008, 13 (2), pp.219-240. 10.1007/s10950-008-9123-1 . hal-00478437

\section{HAL Id: hal-00478437 \\ https://hal.science/hal-00478437}

Submitted on 30 Apr 2010

HAL is a multi-disciplinary open access archive for the deposit and dissemination of scientific research documents, whether they are published or not. The documents may come from teaching and research institutions in France or abroad, or from public or private research centers.
L'archive ouverte pluridisciplinaire HAL, est destinée au dépôt et à la diffusion de documents scientifiques de niveau recherche, publiés ou non, émanant des établissements d'enseignement et de recherche français ou étrangers, des laboratoires publics ou privés. 


\title{
Constraining the anisotropy structure of the crust by joint inversion of seismic reflection travel times and wave polarizations
}

\author{
Jingyi Chen • Jiwen Teng • José Badal
}

Received: 6 June 2007 / Accepted: 10 January 2008 / Published online: 5 September 2008

(C) Springer Science + Business Media B.V. 2008

\begin{abstract}
In the context of wide-angle seismic profiling, the determination of the physical properties of the Earth crust, such as the elastic layer depth and seismic velocity, is often performed by inversion of $\mathrm{P}$ - and/or S-phases propagation data supplying the geometry of the medium (reflector depths) or any other structural parameter (P- or S-wave velocity, density...). Moreover, the inversion for velocity structure and interfaces is commonly performed using only seismic reflection travel times and/or crustal phase amplitudes in isotropic media. But it is very important to utilize more available information to constrain the
\end{abstract}

J. Chen · J. Teng

State Key Laboratory of Lithosphere Evolution, Institute of Geology and Geophysics,

Chinese Academy of Sciences,

Beijing 100029, China

J. Chen

e-mail: jingyichen@mail.iggcas.ac.cn

J. Teng

e-mail: jwteng@mail.iggcas.ac.cn

J. Badal $(\varangle)$

Physics of the Earth, Sciences B,

University of Zaragoza, Pedro Cerbuna 12,

50009 Zaragoza, Spain

e-mail: badal@unizar.es non-uniqueness of the solution. In this paper, we present a simultaneous inversion method of seismic reflection travel times and polarizations data of transient elastic waves in stratified media to reconstruct not only layer depth and vertical P-wave velocity but also the anisotropy feature of the crust based on the estimation of the Thomsen's parameters. We carry out a checking with synthetic data, comparing the inversion results obtained by anisotropic travel-time inversion to the results derived by joint inversion of seismic reflection travel times and polarizations data. The comparison proves that the first procedure leads to biased anisotropic models, while the second one fits nearly the real model. This makes the joint inversion method feasible. Finally, we investigate the geometry, $\mathrm{P}$-wave velocity structure and anisotropy of the crust beneath Southeastern China by applying the proposed inversion method to previously acquired wide-angle seismic data. In this case, the anisotropy signature provides clear evidence that the Jiangshan-Shaoxing fault is the natural boundary between the Yangtze and Cathaysia blocks.

Keywords P-wave travel times • Polarization angles $\cdot$ Joint inversion • Crustal anisotropy $\cdot$ Southeastern China 


\section{Introduction}

Several papers discuss the inversion for crustal velocity structure using seismic reflection travel times (Lutter and Nowack 1990; Zelt and Smith 1992; Pullammanappallil and Louie 1993, 1994, 1997; Bai and Wang 2004) and also the formal inversion for laterally heterogeneous velocity structure from $\mathrm{P}$-wave polarization data $(\mathrm{Hu}$ and William 1992). These papers have two features in common, namely, the assumption of an isotropic seismic velocity model, neglecting any effect coming from seismic anisotropy, and a fixed seismic reflector geometry defining the structure of the layered elastic physical medium. However, seismic anisotropy induced by thin layering (Helbig 1983, 1984; Thomsen 1986) or a cracked solid (Hudson 1980) is widespread in the earth's crust. Bishop et al. (1985) and Samuel (1990) pointed out the velocity-depth ambiguity of reflection travel times that brings about important influence facing the inversion of physical attributes. Even though some authors assume seismic anisotropy (Zhang et al. 2003), they miss out the influence of the depth of the reflecting discontinuity. Thus, neglecting key aspects such as the anisotropic nature of the earth's crust and the depths at which the reflectors lie may lead to distorted images of the subsurface structure even to misinterpretation.

Abundant previous work on seismic anisotropy has been made up to date, from the pioneer studies (Postma 1955; Backus 1962; Berryman 1979; Levin 1979; Helbig 1983, 1984; Crampin 1986; Vidale 1986; Park et al. 1987; Jurkevics 1988; Rommel 1994; Eduardo and Paul 1994; Alkhalifah and Tsvankin 1995; Tsvankin 1996) to more recent papers (Grechka et al. 2001; Yang et al. 2002; Qin et al. 2003a, b). Starting from the fact that the common (weak) anisotropy that is present in the nature is however for transversely isotropic media with a vertical symmetry axis (VTI media), Thomsen (1986) quantified this sort of anisotropy through three basic parameters, namely, $\varepsilon, \delta$, and $\gamma$, which are more intuitive and easier to measure and to be implemented than earlier measures of anisotropy; the parameters $\varepsilon$ and $\delta$ define the Pwave anisotropy while the parameter $\gamma$ controls the S-wave anisotropy. These parameters control most of the anisotropic phenomena of impor- tance in exploration seismology, some of which are non-negligible even though the anisotropy is weak. The critical parameter $\delta$ is an awkward combination of elastic parameters, a combination that is totally independent on horizontal velocity and that may be either positive or negative in a natural context (Thomsen 1986). Some papers discuss in detail the characteristics of VTI media by means of different inversion methods (Byun and Corrigan 1990; Tsvankin and Thomsen 1995; Horne and Leaney 2000; Zhang et al. 2003), although using merely travel times or polarizations data of the propagating seismic waves. As given the non-uniqueness of the inversion result, it is therefore very important to introduce available information for restricting the solution. In this sense, the joint inversion of seismic reflection travel times and wave polarizations is an alternative way opposite to simple inverse modeling from a single dataset.

This paper explores how the wave polarization data can be used to supplement travel-time data in a seismic inversion for anisotropic earth structure. This topic is important because of the well-known inadequacy of travel-time data alone to distinguish anisotropy from heterogeneity. We propose a joint inversion approach based on least squares to obtain anisotropic stiffness coefficients, layer thicknesses, and vertical P-wave velocity in the earth's crust. The implemented method proves that the joint inversion results fit nearly the real model. After processing real data obtained from conventional wide-angle seismic profiling, we provide results concerning vertical $\mathrm{P}$-wave velocity, reflector depths and anisotropy parameters for several crustal structures beneath Southeastern China.

\section{Forward modeling}

Let be a model consisting of $N$ horizontal anisotropic layers of thickness $h_{k}(k=1, \ldots, N)$, and a set of $M$ receivers $R_{i}(i=1, \ldots, M)$ installed at surface for detecting seismic reflections from the reflectors at different depths (Fig. 1). Let us suppose that the seismic reflection from the $k$ th interface is recorded by the $i$ th receiver. The reflection travel-time $T_{i}^{k}$ and the polarization 


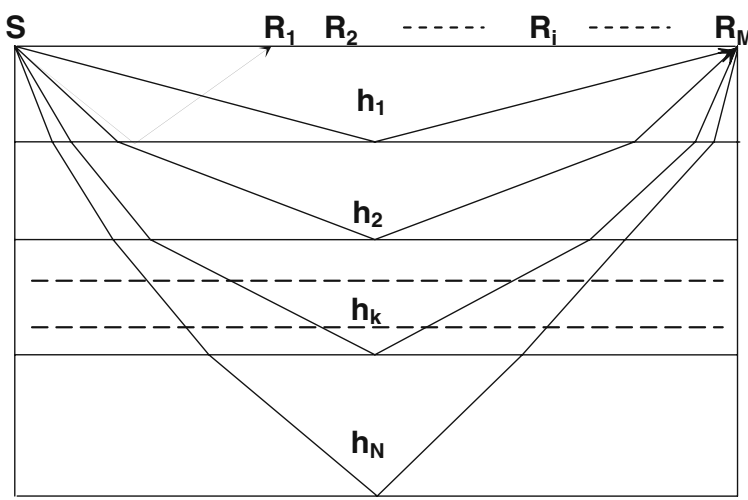

Fig. 1 Schematized earth model consisting of $N$ horizontal anisotropic layers of thickness $h_{k}(k=1, \ldots, N)$. Seismic reflections from different reflectors are registered by a set of $M$ receivers $R_{i}(i=1, \ldots, M)$ installed at surface; $S$ denotes the energy source. Some ray trajectories have been plotted

angle $\gamma_{i}^{k}$ obtained by ray tracing are given by the equations

$$
\begin{aligned}
T_{i}^{k} & =\sum_{j=1}^{k-1} \frac{2 h_{j}}{V_{p i j} \cos \phi_{i j}}+\frac{2 h_{k}}{V_{p i k} \cos \phi_{i k}} \\
\gamma_{i}^{k} & =\frac{\sin \theta_{i k} \cos \theta_{i k}\left(C_{13 k}+C_{55 k}\right)}{\rho_{k} v_{p i k}^{2}-C_{11 k} \sin ^{2} \theta_{i k}-C_{55 k} \cos ^{2} \theta_{i k}}
\end{aligned}
$$

and the offset equation is expressed as

$$
x_{i}=\sum_{j=1}^{k-1} 2 h_{j} \tan \phi_{i j}+2 h_{k} \tan \phi_{i k}
$$

where $V_{p i k}, v_{p i k}, \phi_{i k}$, and $\theta_{i k}$ are the P-wave group velocity, phase velocity, the group angle, and the phase angle associated to the ray arriving at the $i$ th receiver from the $k$ th layer, respectively; $h_{k}$ and $\rho_{k}$ are the thickness and density of the $k$ th layer, and $C_{11 k}, C_{13 k}$, and $C_{55 k}$ are the anisotropic stiffness coefficients for this layer.

The velocities $\mathrm{V}_{p i k}$ and $v_{p i k}$ and the angle $\phi_{i k}$ are written as (Thomsen 1986)

$$
\begin{aligned}
& V_{p i k}^{2}\left(\phi_{i k}\left(\theta_{i k}\right)\right)=V_{p i k}^{2}\left(\theta_{i k}\right)+\left(\frac{d v_{p i k}}{d \theta_{i k}}\right)^{2} \\
& v_{p i k}\left(\theta_{i k}\right)=v_{p 0 k}\left(1+\delta_{k} \sin ^{2} \theta_{i k}+\left(\varepsilon_{k}-\delta_{k}\right) \sin ^{4} \theta_{i k}\right)
\end{aligned}
$$

$\tan \left(\phi_{i k}\left(\theta_{i k}\right)\right)=\left(\tan \theta_{i k}+\frac{1}{v_{p i k}} \frac{d v_{p i k}}{d \theta_{i k}}\right) /\left(1-\frac{\tan \theta_{i k}}{v_{p i k}} \frac{d v_{p i k}}{d \theta_{i k}}\right)$

where $v_{p 0 k}$ is the vertical $\mathrm{P}$-wave velocity in the $k$ th layer.

The vertical P-wave velocity $v_{p 0 k}$ and the Thomsen's parameters $\varepsilon_{k}$ and $\delta_{k}$ are expressed as (Thomsen 1986)

$$
\begin{aligned}
& v_{p 0 k}=\sqrt{\frac{C_{33 k}}{\rho_{k}}} \\
& \varepsilon_{k}=\frac{C_{11 k}-C_{33 k}}{2 C_{33 k}} \\
& \delta_{k}=\frac{\left(C_{13 k}+C_{55 k}\right)^{2}-\left(C_{33 k}-C_{55 k}\right)^{2}}{2 C_{33 k}\left(C_{33 k}-C_{55 k}\right)}
\end{aligned}
$$

The phase angle $\theta_{i k}$ is necessary to calculate the reflection travel-time $T_{i}^{k}$ and the polarization angle $\gamma_{i}^{k}$. Snell's law, which states that the horizontal slowness of the transient wave is preserved on reflection for media with smoothly varying depthdependence of velocity, establishes that

$p=\frac{\sin \theta_{i 1}}{v_{p i 1}}=\frac{\sin \theta_{i 2}}{v_{p i 2}}=\cdots=\frac{\sin \theta_{i k}}{v_{p i k}}=\cdots$

which is the condition that the reflecting and transmitting seismic waves must satisfy; here, $p$ is called the ray parameter and $\theta_{i k}$ denotes the phase angle for the incident, reflecting or transmitting wave from the $k$ th reflector. We perform the following ray-tracing approach: the ray parameter $p$ in Eq. 10 can be determined considering a very small sample phase angle $\theta_{i 1}$ and the phase velocity $v_{p i 1}$ for the first layer; any phase angle $\theta_{i k}$ associated to the ray theoretically arriving at the $i$ th receiver from the $k$ th layer can be obtained from the phase velocities $v_{\text {pik }}$ that define the starting model. Ray-path group angles and velocities can be computed by Eqs. 4, 5, and 6 and the offset $d_{1} \neq x_{i}$, $d_{1}-x_{i} \leq 0$, by Eq. 3. Allowing for a quite larger sample value $\theta_{i 1}^{*} \gg \theta_{i 1}$ and repeating the precedent operations, we obtain a new offset $d_{2} \neq x_{i}$, so that $d_{2}-x_{i} \geq 0$. In a second step, we take a new phase angle $\theta_{i 1}^{* *}$ with the restriction $\theta_{i 1}<\theta_{i 1}^{* *}<\theta_{i 1}^{*}$ and do the same operations again and so on by successive approximations up to obtain very close 
offsets or a difference $d-x_{i} \leq$ error expectancy (for example, $10^{-6} \mathrm{~km}$ ). Finally, the reflection travel-time $T_{i}^{k}$ and the polarization angle $\gamma_{i}^{k}$ can be calculated using Eqs. 1 and 2.

\section{Inverse modeling}

We first carry out inversion for the anisotropic stiffness coefficients of the $k$ th layer and after we compute seismic velocity and Thomsen's parameters by Eqs. 7, 8, and 9. It is assumed that the anisotropic stiffness parameters above this layer and an initial model for the $k$ th layer are known. Considering the $i$ th receiver and the $k$ th interface the reflection travel time and polarization-misfit functions can be written as

$$
\begin{aligned}
\Delta T_{i}^{k}= & T_{i}^{k}-T_{i 0}^{k}=\frac{\partial T_{i}^{k}}{\partial C_{11 k}} \Delta C_{11 k}+\frac{\partial T_{i}^{k}}{\partial C_{13 k}} \Delta C_{13 k} \\
& +\frac{\partial T_{i}^{k}}{\partial C_{33 k}} \Delta C_{33 k}+\frac{\partial T_{i}^{k}}{\partial h_{k}} \Delta h_{k} \\
& +O\left(\Delta C_{11 k}, \Delta C_{13 k}, \Delta_{33 k}, \Delta h_{k}\right) \\
\Delta \gamma_{i}^{k}= & \gamma_{i}^{k}-\gamma_{i 0}^{k}=\frac{\partial \gamma_{i}^{k}}{\partial C_{11 k}} \Delta C_{11 k}+\frac{\partial \gamma_{i}^{k}}{\partial C_{13 k}} \Delta C_{13 k} \\
& +\frac{\partial \gamma_{i}^{k}}{\partial C_{33 k}} \Delta C_{33 k}+\frac{\partial \gamma_{i}^{k}}{\partial h_{k}} \Delta h_{k} \\
& +O\left(\Delta C_{11 k}, \Delta C_{13 k}, \Delta 33 k, \Delta h_{k}\right)
\end{aligned}
$$

where $T_{i 0}^{k}$ and $\gamma_{i 0}^{k}$ are the computed reflection travel time and polarization, respectively; the symbol $\partial$ means partial differentiation, and $O\left(\Delta C_{11 k}, \Delta C_{13 k}, \Delta_{33 k}, \Delta h_{k}\right)$ expresses higher order terms than the first-order derivatives. In these last equations, the symbol $\Delta$ before the variables refers to small perturbations in those variables, which determine fluctuations in $T_{i}^{k}$ and $\gamma_{i}^{k}$ in accordance with an approximate linear relationship. The left members of the above equations give the differences between ray travel times and polarization angles and their respective theoretical values obtained from the initial model. The small changes in the variables accompanying the firstorder terms in the above Taylor expansions are just the unknowns to be determined.
For the $M$ receivers that record reflections from the $k$ th interface, Eq. 11 can be written time and again, thus obtaining the following linear equation system given in matrix form:

This system in partial derivatives can be rewritten as

$F=A \Delta C_{11 k}+B \Delta C_{13 k}+C \Delta C_{33 k}+D \Delta h_{k}$

where both the data space vector (left member, $2 M$ components) and the rest of matrices are

$$
\begin{aligned}
F & =\left(\Delta T_{1}^{k} \cdots \cdots \Delta T_{M}^{k} \Delta \gamma_{1}^{k} \cdots \cdots \Delta \gamma_{M}^{k}\right)^{T} \\
A & =\left(\frac{\partial T_{1}^{k}}{\partial C_{11 k}} \cdots \cdots \frac{\partial T_{M}^{k}}{\partial C_{11 k}} \frac{\partial \gamma_{1}^{k}}{\partial C_{11 k}} \cdots \cdots \frac{\partial \gamma_{M}^{k}}{\partial C_{11 k}}\right)^{T} \\
B & =\left(\frac{\partial T_{1}^{k}}{\partial C_{13 k}} \cdots \cdots \frac{\partial T_{M}^{k}}{\partial C_{13 k}} \frac{\partial \gamma_{1}^{k}}{\partial C_{13 k}} \cdots \cdots \frac{\partial \gamma_{M}^{k}}{\partial C_{13 k}}\right)^{T} \\
C & =\left(\frac{\partial T_{1}^{k}}{\partial C_{33 k}} \cdots \cdots \frac{\partial T_{M}^{k}}{\partial C_{33 k}} \frac{\partial \gamma_{1}^{k}}{\partial C_{33 k}} \cdots \cdots \frac{\partial \gamma_{M}^{k}}{\partial C_{33 k}}\right)^{T} \\
D & =\left(\frac{\partial T_{1}^{k}}{\partial h_{k}} \cdots \cdots \frac{\partial T_{M}^{k}}{\partial h_{k}} \frac{\partial \gamma_{1}^{k}}{\partial h_{k}} \cdots \frac{\partial \gamma_{M}^{k}}{\partial h_{k}}\right)^{T}
\end{aligned}
$$


Multiplying Eq. 13 successively by the matrices $A^{T}, B^{T}, C^{T}$ and $D^{T}$ we have

$$
\begin{aligned}
A^{T} F= & A^{T} A \Delta C_{11 k}+A^{T} B \Delta C_{13 k} \\
& +A^{T} C \Delta C_{33 k}+A^{T} D \Delta h_{k} \\
B^{T} F= & B^{T} A \Delta C_{11 k}+B^{T} B \Delta C_{13 k} \\
& +B^{T} C \Delta C_{33 k}+B^{T} D \Delta h_{k} \\
C^{T} F= & C^{T} A \Delta C_{11 k}+C^{T} B \Delta C_{13 k} \\
& +C^{T} C \Delta C_{33 k}+C^{T} D \Delta h_{k} \\
D^{T} F= & D^{T} A \Delta C_{11 k}+D^{T} B \Delta C_{13 k} \\
& +D^{T} C \Delta C_{33 k}+D^{T} D \Delta h_{k}
\end{aligned}
$$

where the term $A^{T} F$ and the coefficient $A^{T} A$ are both real numbers and the same for other similar terms and coefficients. The system (Eq. 15) can be expressed in compact form as

$$
G x=d
$$

being

$$
\begin{aligned}
x & =\left(\begin{array}{llll}
\Delta C_{11 k} & \Delta C_{13 k} & \Delta C_{33 k} & \Delta h_{k}
\end{array}\right)^{T} \\
d & =\left(\begin{array}{llll}
A^{T} F & B^{T} F & C^{T} F & \left.D^{T} F\right)^{T} \\
G & =\left(\begin{array}{llll}
A^{T} A & A^{T} B & A^{T} C & A^{T} D \\
B^{T} A & B^{T} B & B^{T} C & B^{T} D \\
C^{T} A & C^{T} B & C^{T} C & C^{T} D \\
D^{T} A & D^{T} B & D^{T} C & D^{T} D
\end{array}\right)
\end{array}\right.
\end{aligned}
$$

The resulting $4 \times 4$ algebraic equation system (Eq. 16) can be solved without excessive difficulty. The classic least-squares solution is given by $x=\left(G^{T} G\right)^{-1} G^{T} d$, which is adequate if $\left(G^{T} G\right)^{-1}$ exists. However, we take the best solution to the linear inverse problem subject to the constraint that the size of $x$ is kept small, so that the damped least-squares solution vector $x$ in the model space is found minimizing the sum of the squares of data
Fig. 2 Flowchart describing the computation steps involved in the linear approach

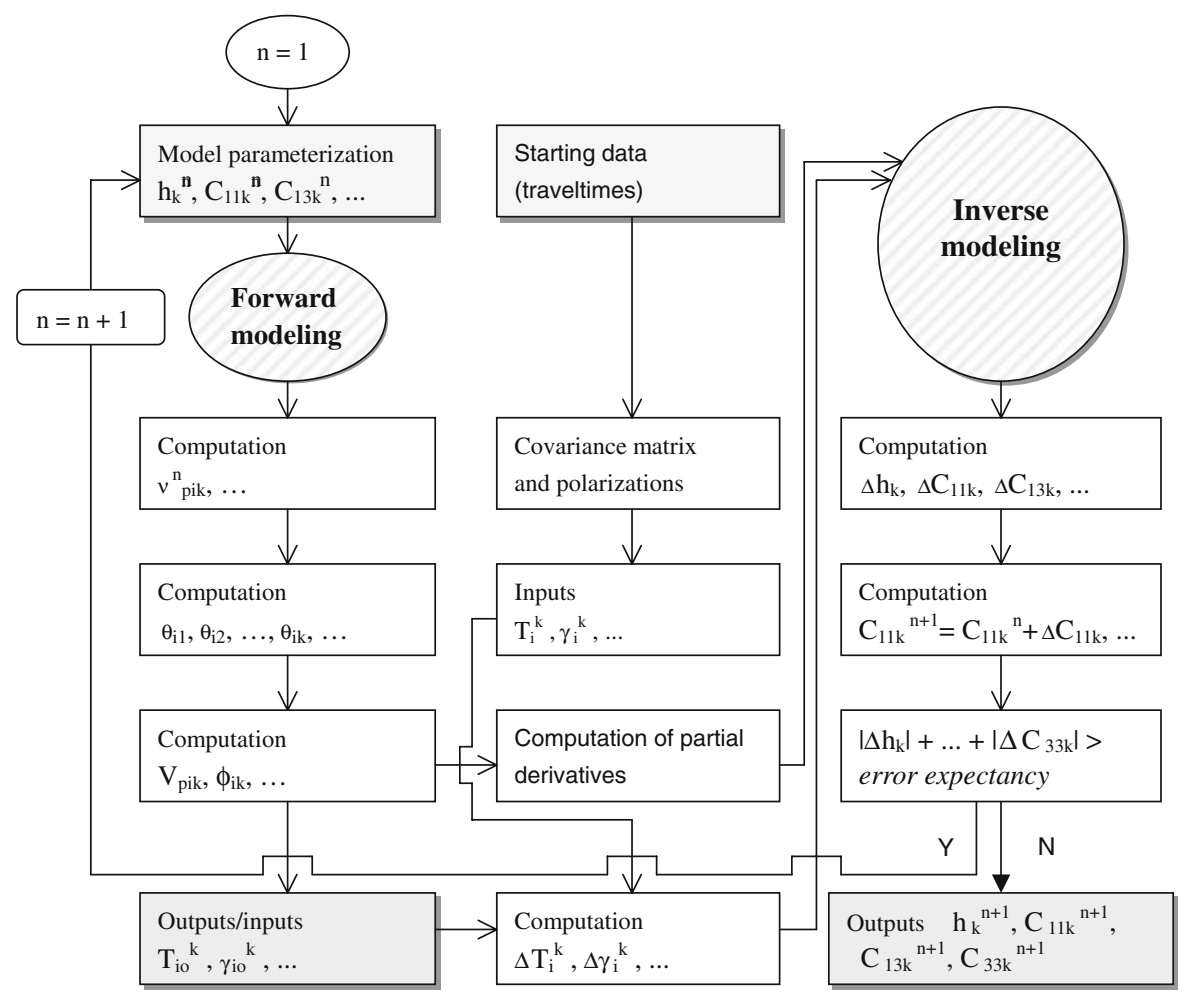


Table 1 Parameterization of the initial upper-crust model used for checking

\begin{tabular}{llllrrr}
\hline Layer number & $h(\mathrm{~km})$ & $\rho\left(\mathrm{Mg} / \mathrm{m}^{3}\right)$ & $C_{11}(\mathrm{Gpa})$ & $C_{13}(\mathrm{Gpa})$ & $C_{33}(\mathrm{Gpa})$ & $C_{55}(\mathrm{Gpa})$ \\
\hline 1st layer & 2.5 & 2.0 & 30.2 & 3.2 & 21.7 & 6.3 \\
2nd layer & 2.5 & 2.0 & 27.7 & -21.9 & 22.7 & 6.7 \\
3rd layer & 2.5 & 2.0 & 39.7 & 16.8 & 28.8 & 8.6 \\
4th layer & 2.5 & 2.0 & 45.0 & 12.9 & 38.8 & 12.9 \\
\hline
\end{tabular}

$h$ Layer thickness, $\rho$ density; $C_{11}, C_{13}, C_{33}, C_{55}$, anisotropic stiffness coefficients

residual and model parameter (Pavlis and Booker 1980; Spencer and Gubbins 1980)

$$
\begin{aligned}
|d-G x|^{2}+|\Theta x|^{2}= & {[G x-d]^{T}[G x-d] } \\
& +\Theta^{2} x^{T} x=\text { MIN }
\end{aligned}
$$

where $\Theta$ represents a trade-off parameter called damping factor.

The model space vector so obtained allows updating the anisotropic model

$$
\begin{aligned}
& C_{11 k}^{n+1}=C_{11 k}^{n}+\Delta C_{11 k}, C_{13 k}^{n+1}=C_{13 k}^{n}+\Delta C_{13 k} \\
& C_{33 k}^{n+1}=C_{33 k}^{n}+\Delta C_{33 k}, h_{k}^{n+1}=h_{k}^{n}+\Delta h_{k}
\end{aligned}
$$

where $n$ denotes the iteration number. The inversion is repeated iteratively up to the sum $\left|\Delta C_{11 k}\right|+\left|\Delta C_{13 k}\right|+\left|\Delta C_{33 k}\right|+\left|\Delta h_{k}\right|$ of the absolute values obtained by the last iteration, is less than the error expectancy and there is no further convergence. The set of stiffness coefficients is then taken as the final solution. A flowchart describing the steps involved in forward and inverse modeling, which makes possible a better understanding of the computation algorithm, can be seen in Fig. 2. Finally, we obtain the vertical P-wave velocity and the Thomsen's parameters of the VTI medium using Eqs. 7, 8, and 9.

\section{Checking with synthetic data}

In order to show how the polarizations data can be used in addition to travel-times data for anisotropic inversion, let be a $20 \times 10 \mathrm{~km}^{2}$ sized VTI model consisting of four horizontal layers of constant thickness $2.5 \mathrm{~km}$. The seismic energy source is just the origin of the coordinate system placed at surface, and the receivers are regularly spaced from 1 to $20 \mathrm{~km}$. The values taken by the physical variables that define the hypothesized upper crust model, including the anisotropy parameters, i.e., $C_{11}, C_{13}$, and $C_{33}$, are listed in Table 1 . The reflection travel times and polarization angles depending on the offset were computed by ray tracing, and the corresponding curves for the four layers of the model are plotted in Fig. 3. Anomalous polarization angles (Helbig and
Fig. 3 Reflection traveltimes and polarization angles as derived by forward modeling from the model given in Table 1. $N$ varying from 1 to 4 identifies each layer of the model
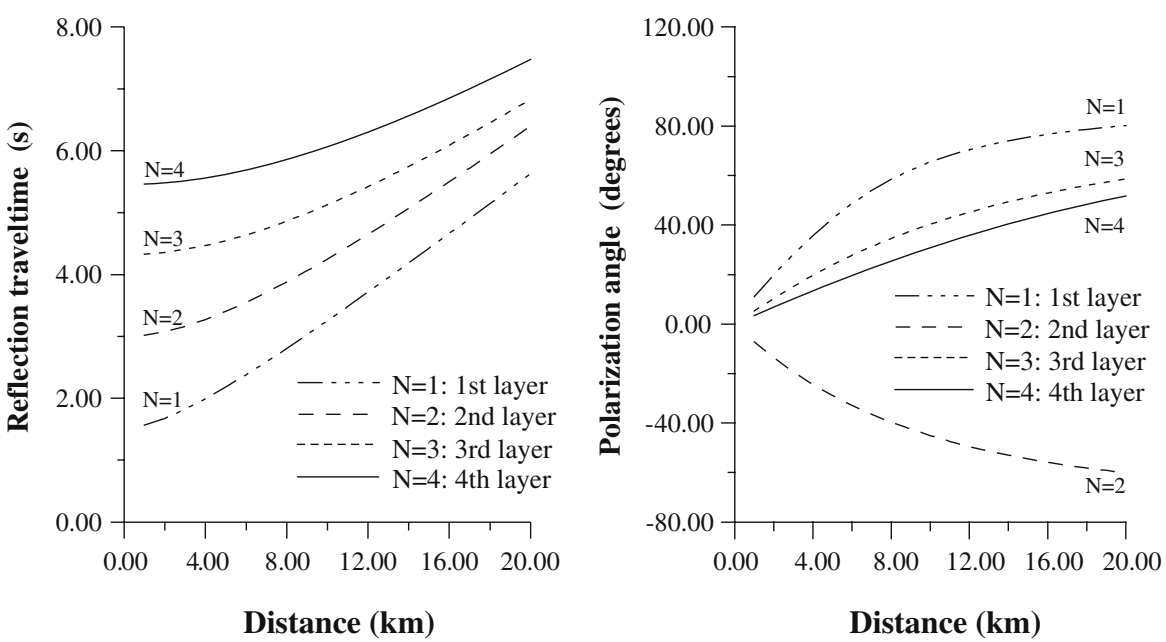
Fig. 4 Anisotropic stiffness coefficients $C_{11}$ (a), $C_{33}$ (b), and $C_{13}$ (c) as derived by anisotropic travel-time inversion (dash lines) and coefficient $C_{13}$ (d) as obtained by anisotropic joint inversion of travel times and polarizations (dash line), contrasted with the depth-dependent curves (solid lines) depicting the parameterized model given in Table 1
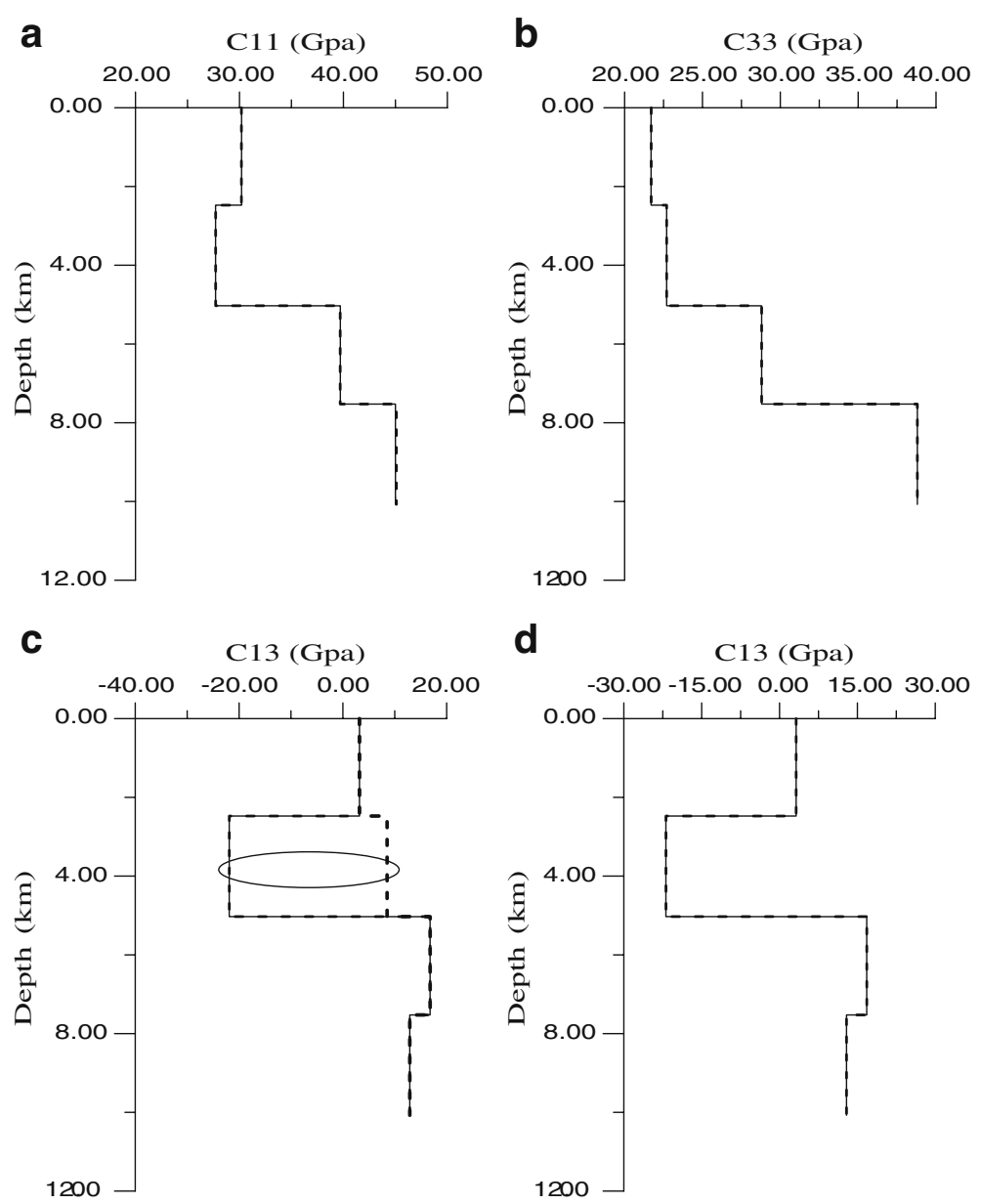

Schoenberg 1987) can be observed for the second layer (labeled $N=2$ in the graphic illustration).

For checking the proposed inversion method, we first perform anisotropic travel-time inver- sion and then anisotropic joint inversion of seismic reflection travel times and polarizations data. From the adopted values of layer thickness and anisotropic coefficients of the initial model, we
Fig. 5 Vertical P-wave velocity (a) and Thomsen parameters (b and c) obtained by joint inversion of travel times and polarizations (dash lines) contrasted with the depth-dependent curves (solid lines) computed from the parameterized model given in Table 1 $\mathbf{a}$

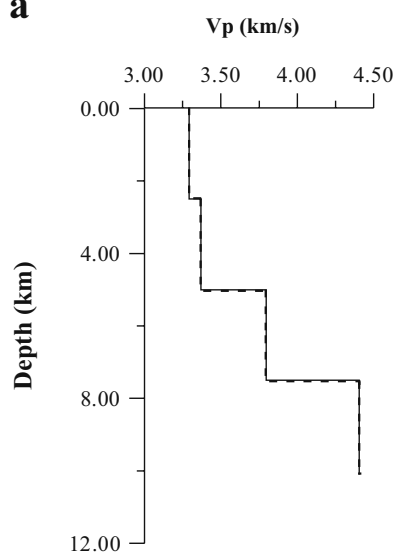

b

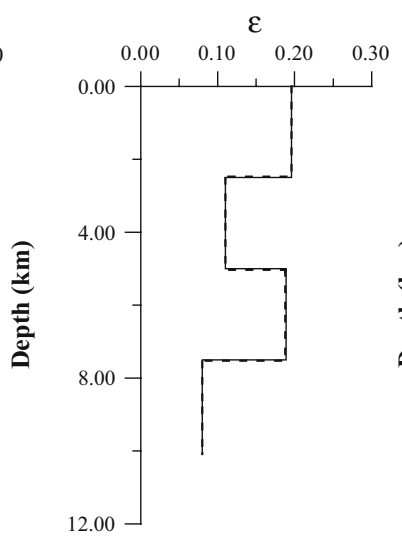

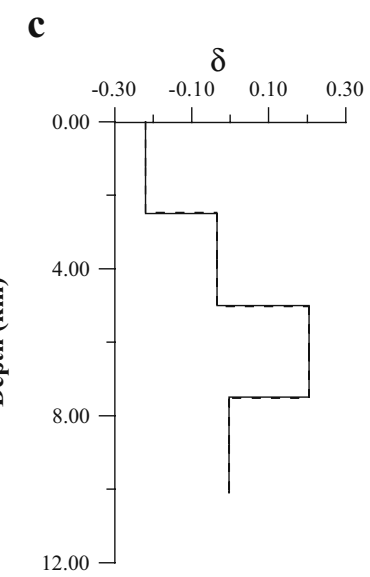


calculate reflection travel times and polarization angles with the analytical expressions formulated for forward modeling, whose values are in his turn taken as input data to start any of the two inversion processes mentioned above. The results achieved after using both inversion approaches are plotted in Fig. 4. Figure $4 a-c$ shows the re- sults obtained when only anisotropic travel-time inversion is made: in particular, the coefficient $C_{13}$ concerning the second layer of the model differ remarkably from its value in the real model. In change, Fig. 4d shows the solution obtained to this respect by joint inversion: We now see an unbiased result for the coefficient $C_{13}$ that fits

$\begin{array}{llll}118 & 119 & 120 & 121\end{array}$

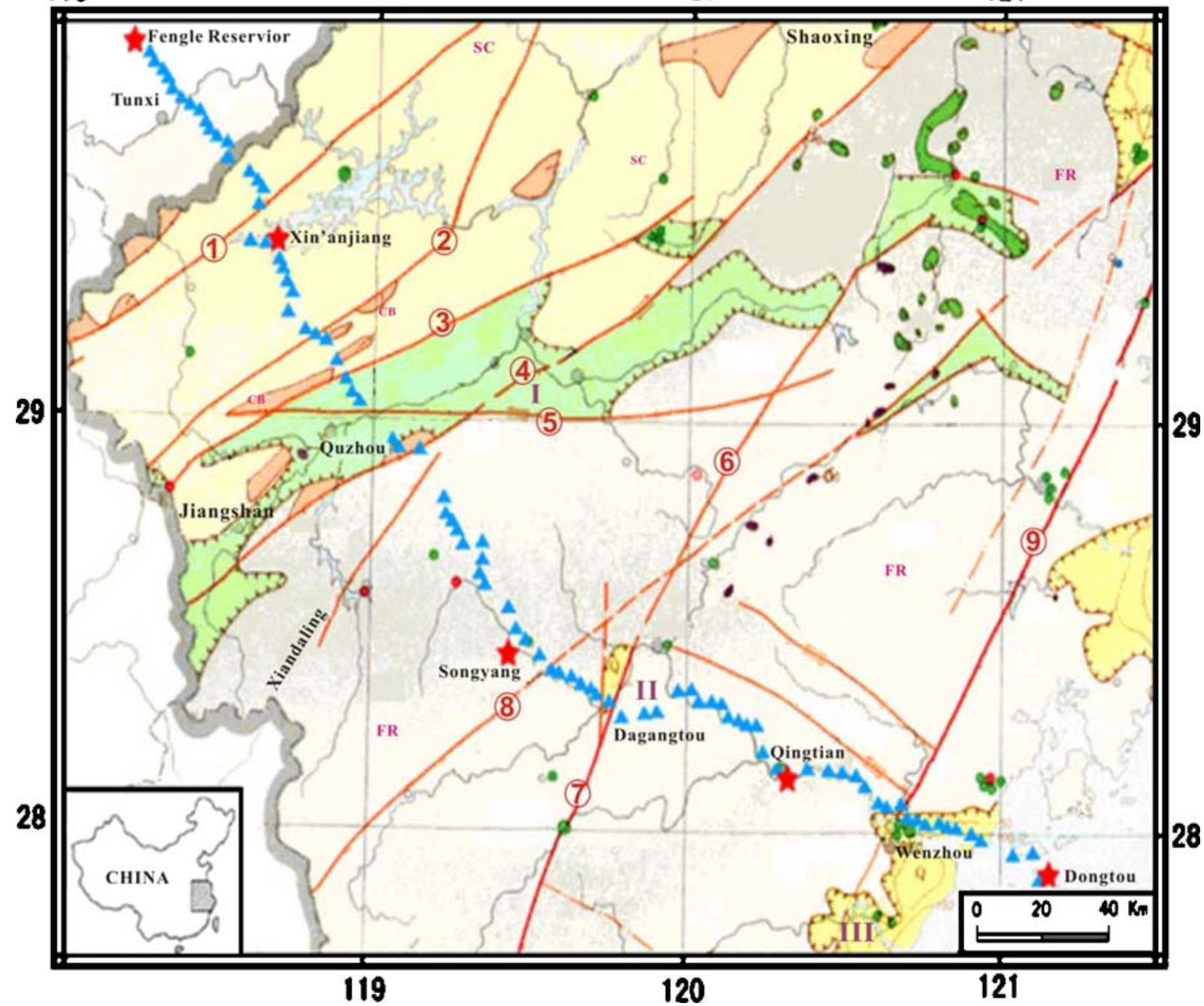

Fig. 6 Simplified situation map of Southeastern China and neighboring areas showing the wide-angle seismic profile in NW-SE direction from Fengle Reservoir (near Tunxi) to Dongtou Island (near Wenzhou). The inset in the bottom left corner indicates the location of the study area (shaded zone). Up to 85 portable seismic stations (triangles) were installed and five shots were fired at different sites (stars): Fengle, Xinanjiang, Songyang, Qingtian, and Dongtou. The major active faults crossed by the long linear antenna are: Lin'an-Majin-Wuzhen fault (1), Wuxing-Jiande fault (2), Changshan-Pujiang fault (3), Jiangshan-Shaoxing fault (4), Quzhou-Tangxian fault (5), Shangyu-Lishui fault (6), Qingyuan-Anren fault (7), Ningbo-Longquan fault (8), Zhenhai-Wenzhou fault (9). The profile also crosses sedimentary basins, such as the Jinqu Basin (I), the Bihu Basin (II) and the WenzhouPingyang Hollow (III) 
Fig. 7 Three-component $\mathrm{P}$-wave record sections at reduced time scale showing the propagating seismic phases from the shots fired at Fengle $(F L)$, Xinanjiang $(X A)$,

Songyang $(S Y)$,

Qingtian $(Q T)$, and Dongtou $(D T)$
FL-X

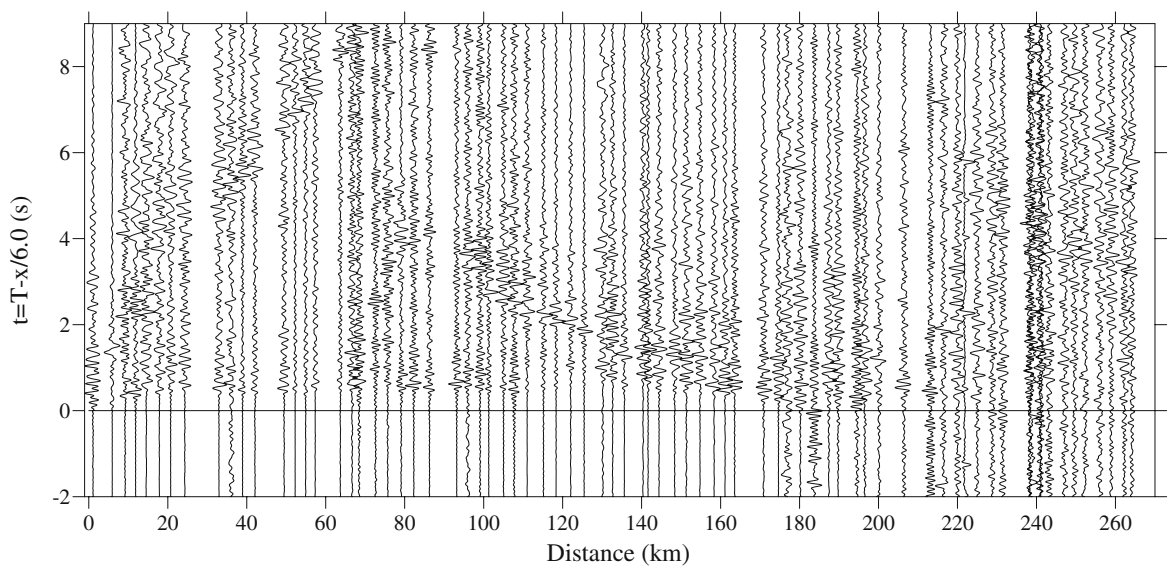

FL-Y

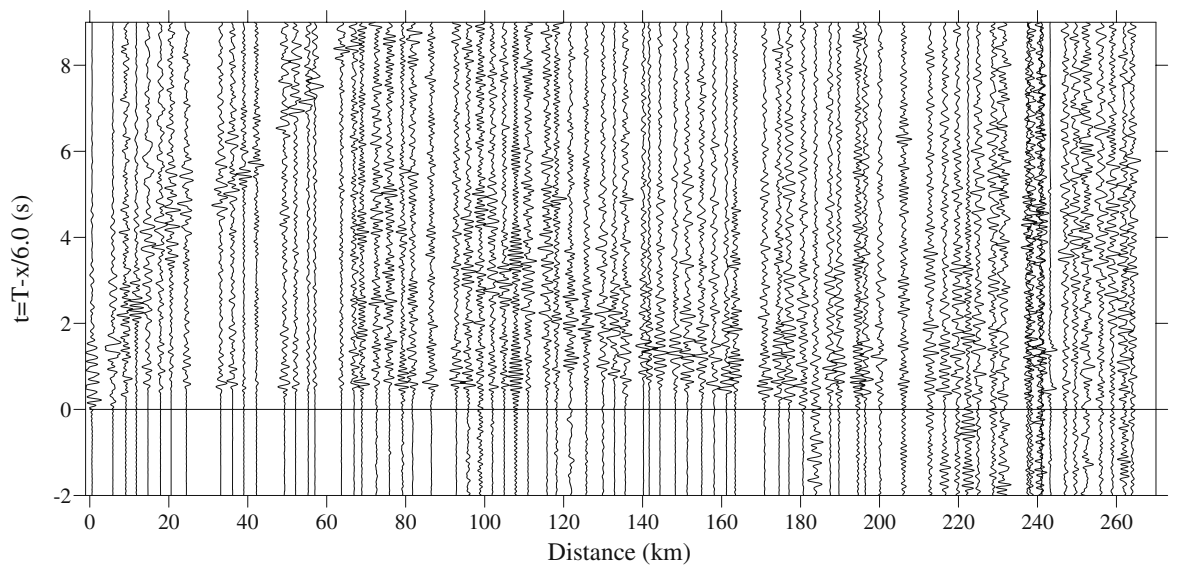

FL-Z

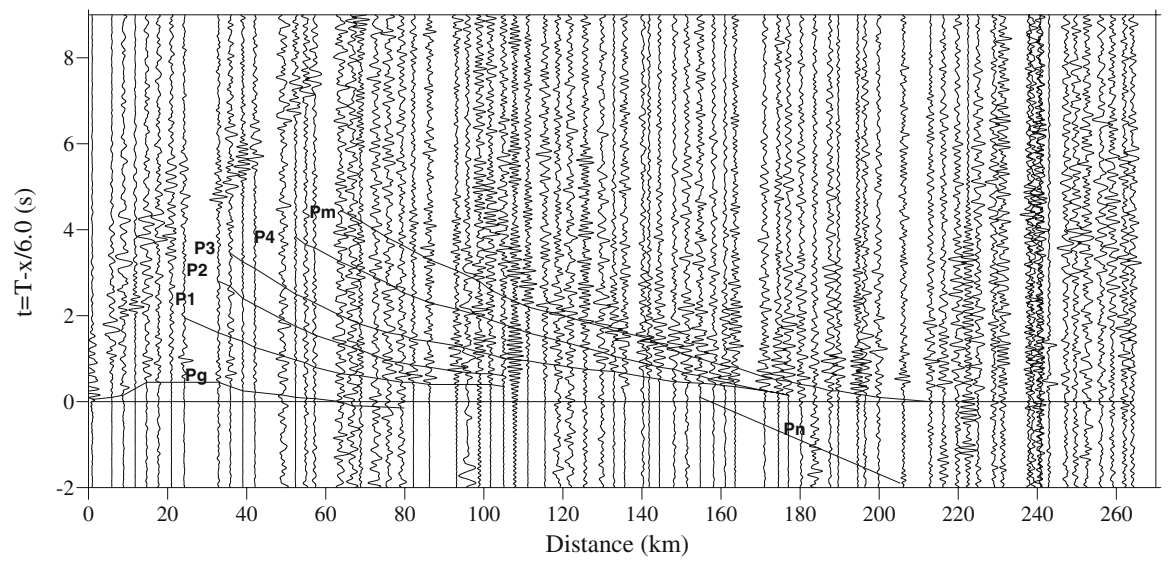

completely the real model. In Fig. 5, we have represented the depth-dependence of the P-wave velocity and the Thomsen's parameters obtained by joint inversion and Eqs. 7, 8, and 9: These results fit the real model too. These inversion results demonstrate that the joint inversion can effectively constrain the non-uniqueness of the solution. 
Fig. 7 (continued)

XA-X

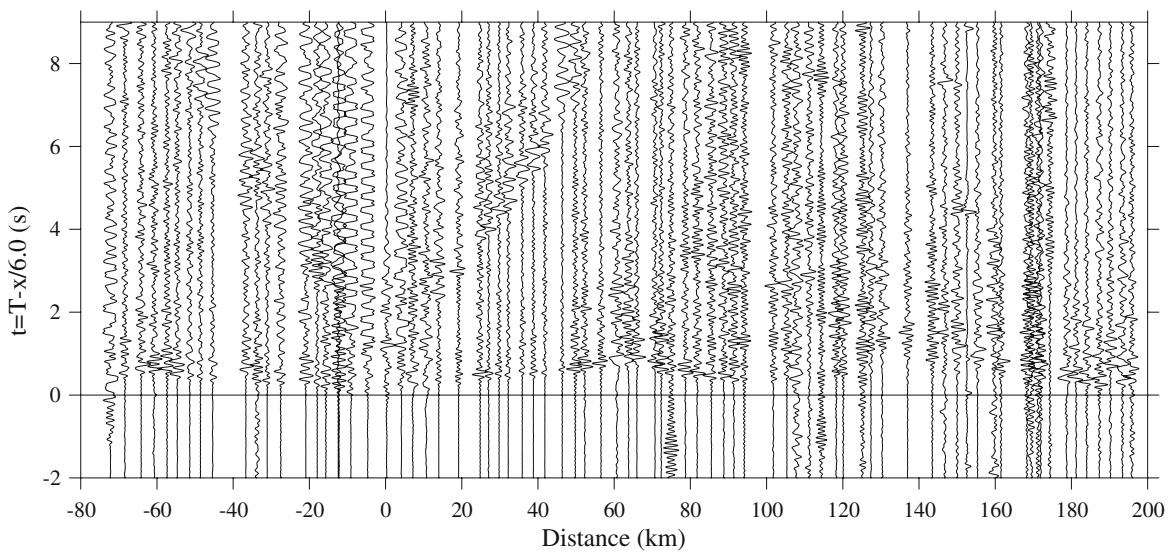

XA-Y

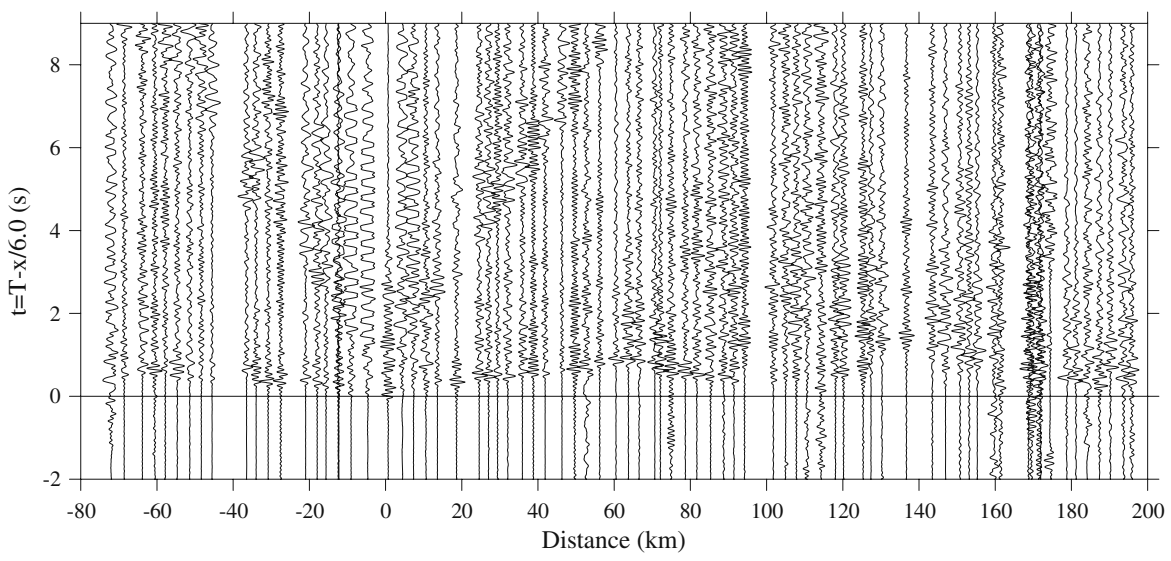

XA-Z

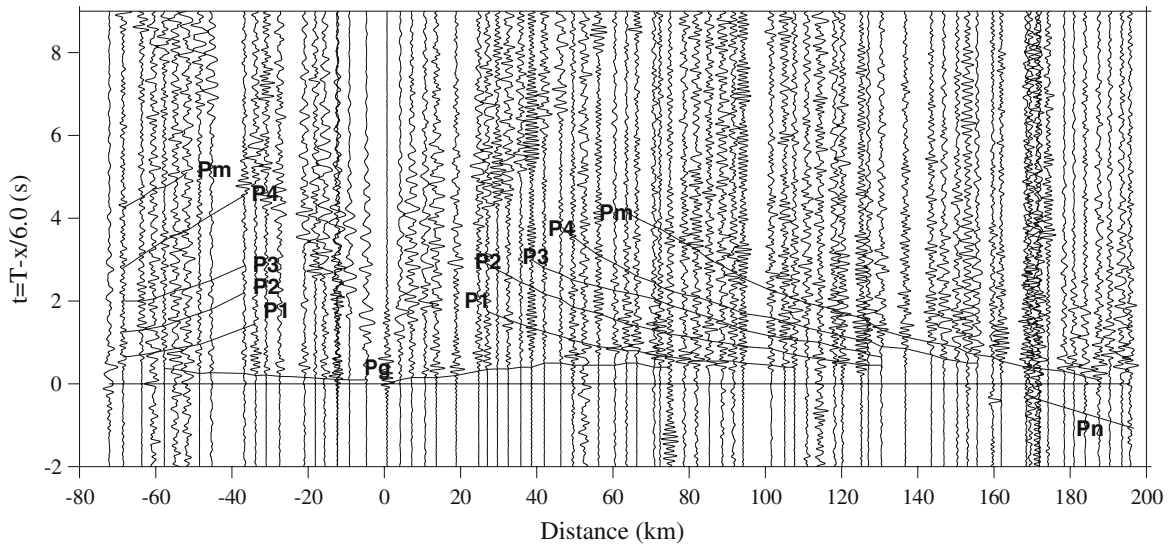


Fig. 7 (continued)

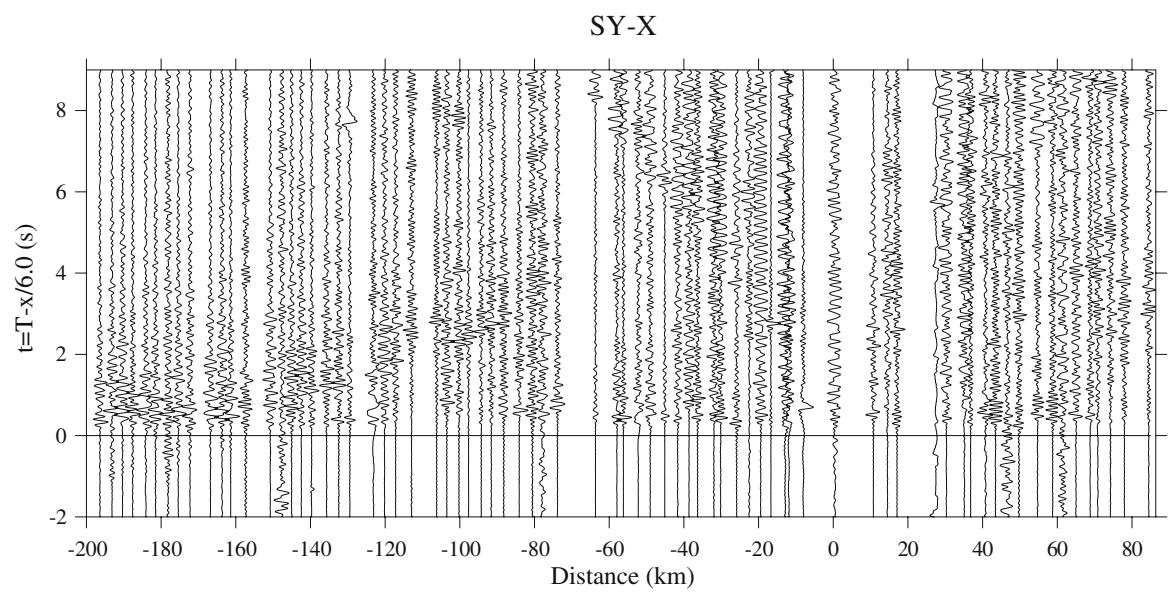

SY-Y

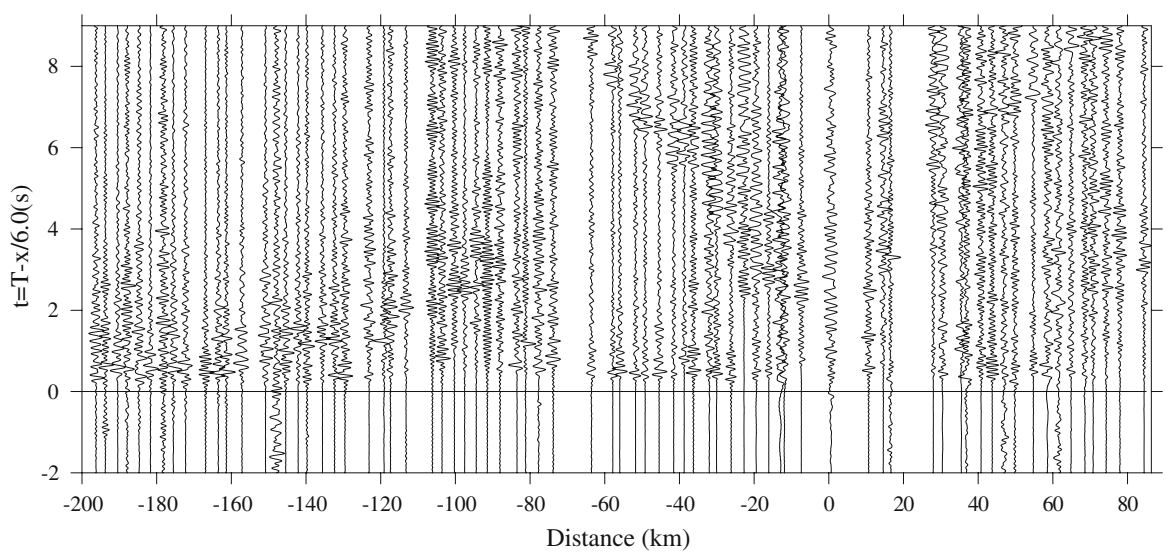

SY-Z

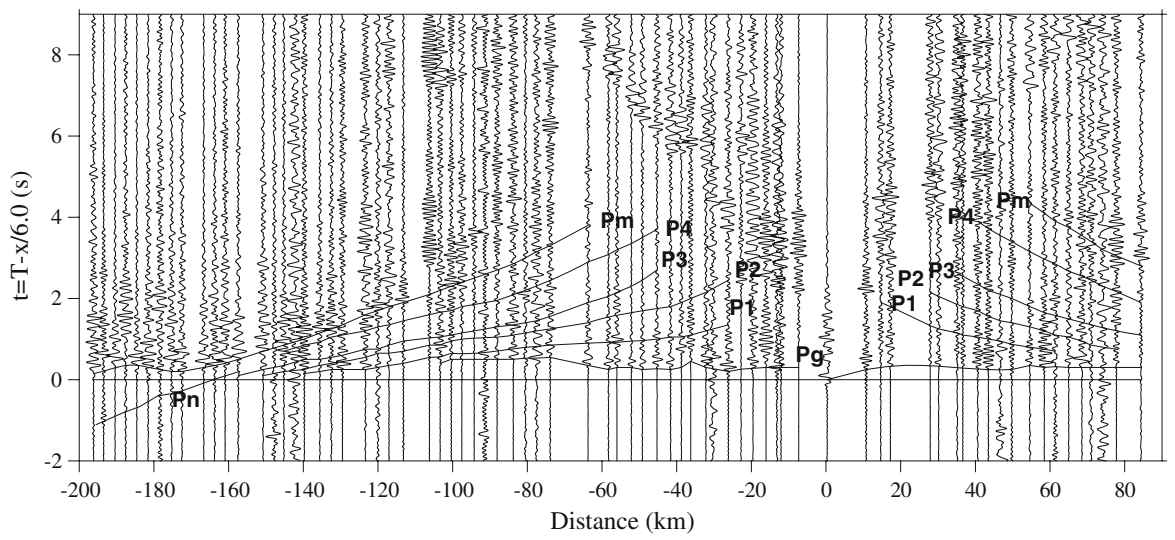


Fig. 7 (continued)

QT-X

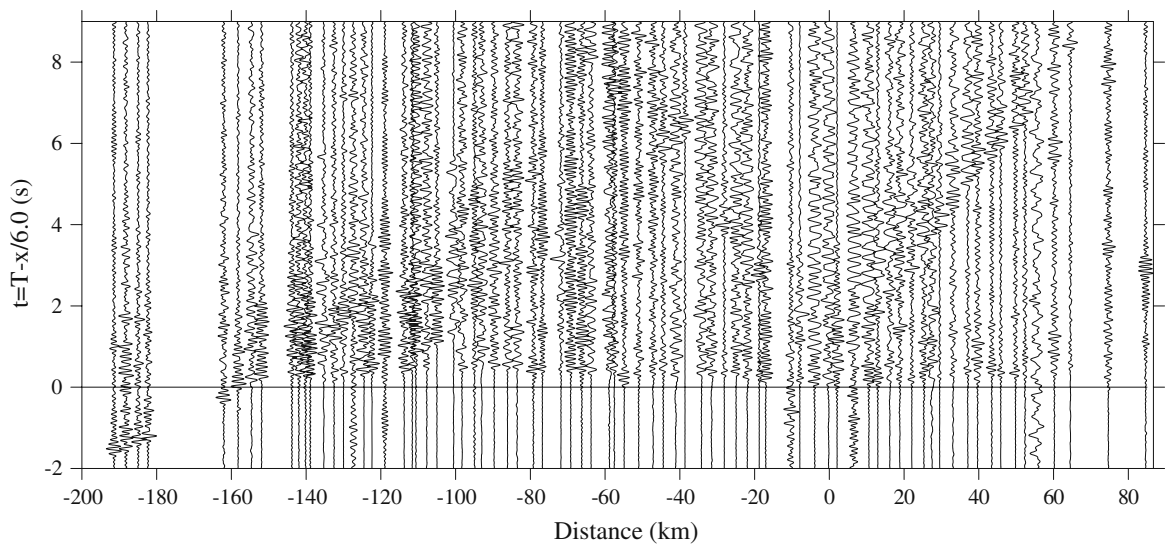

QT-Y

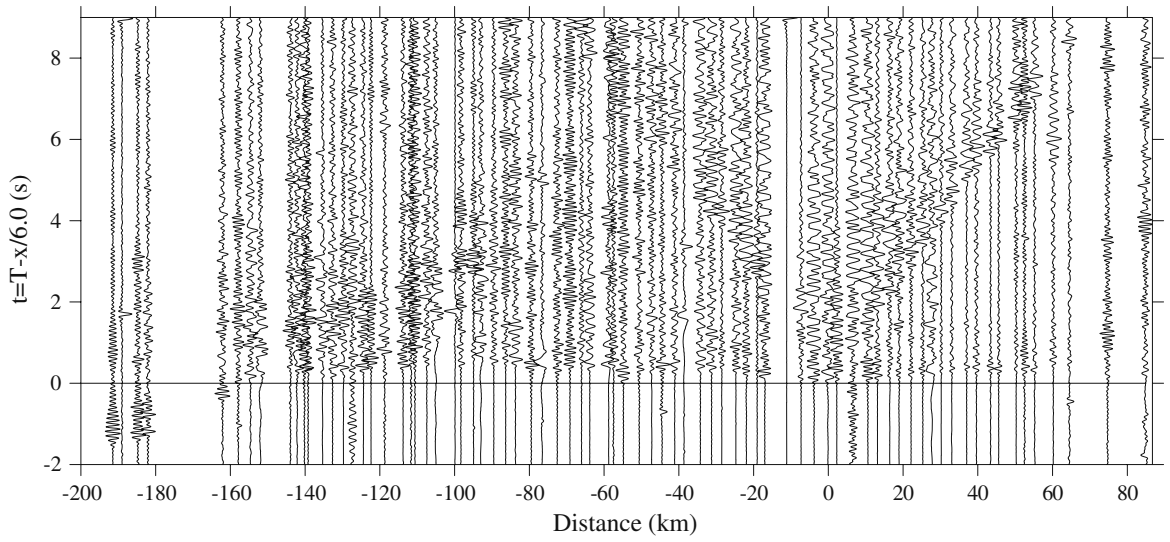

QT-Z

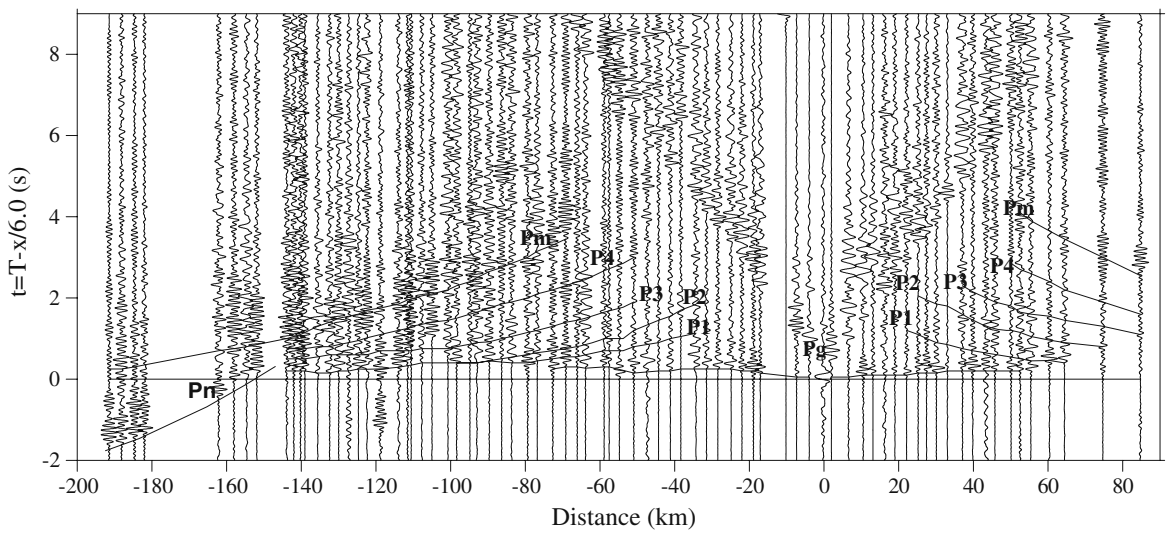


Fig. 7 (continued)

DT-X

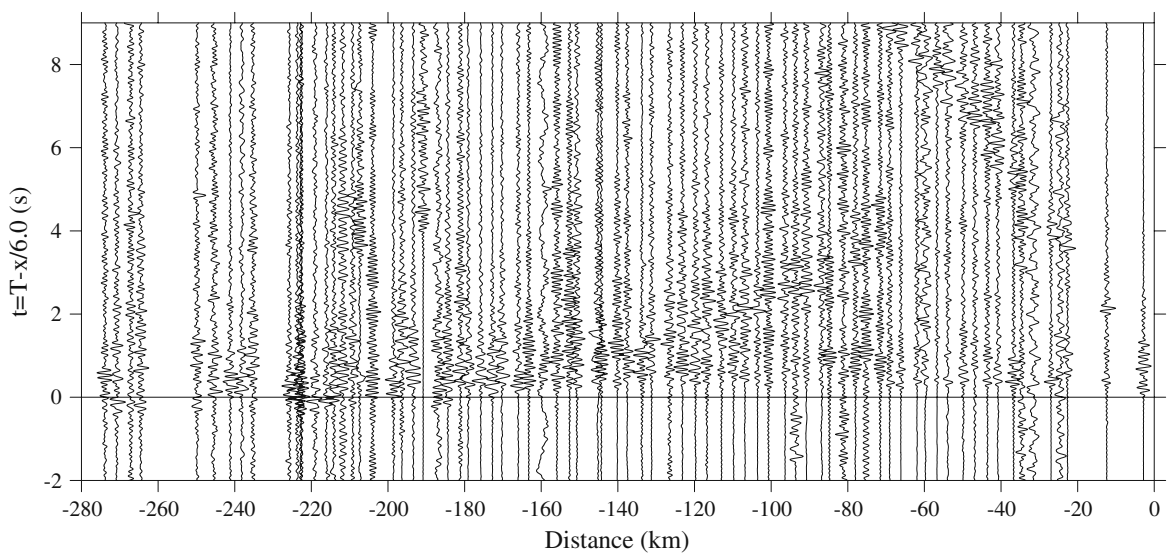

DT-Y

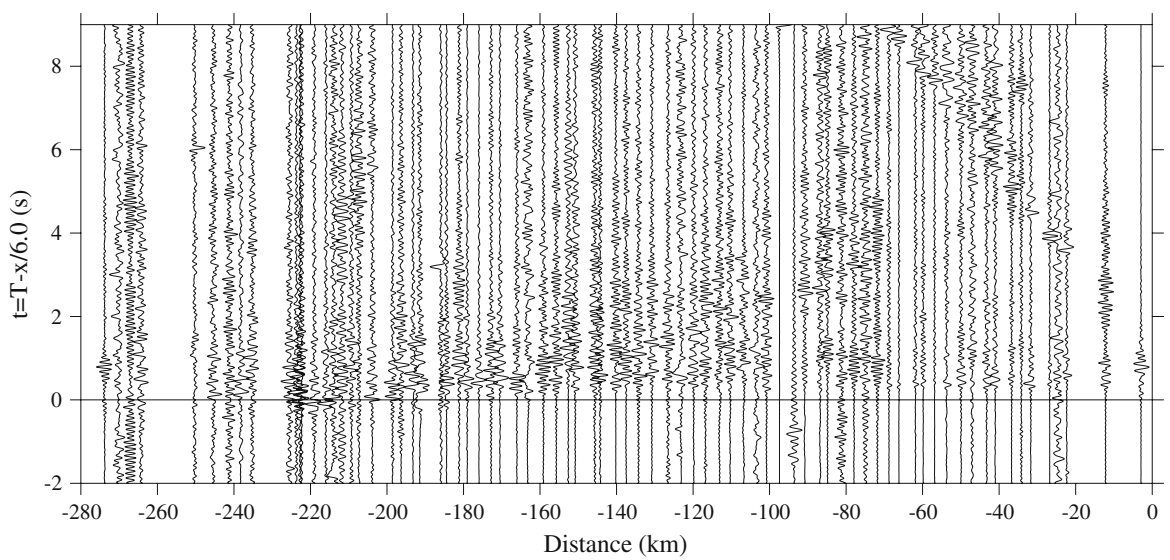

DT-Z

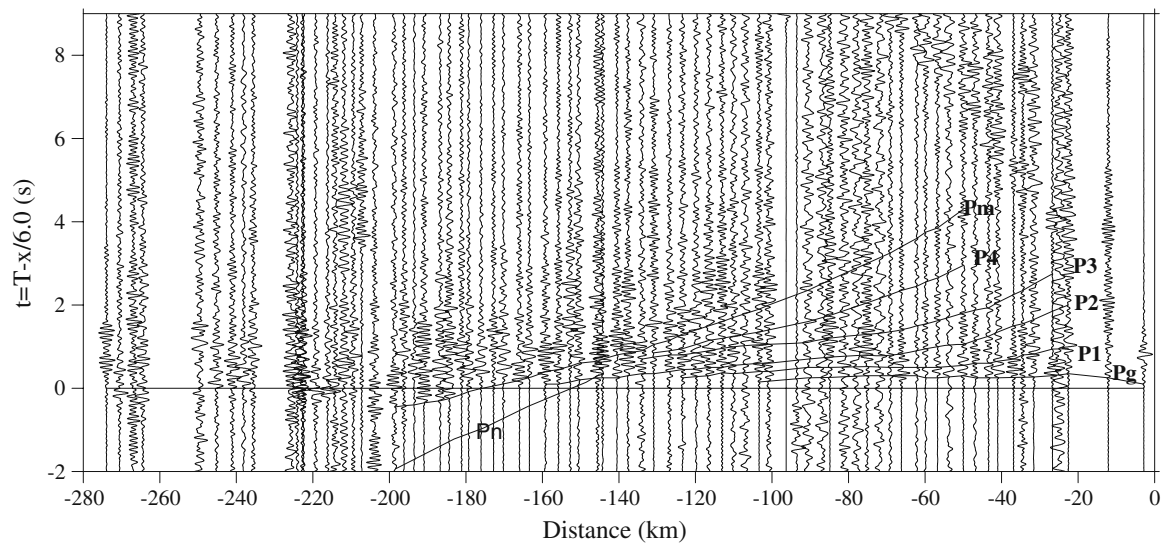




\section{Application to real data: anisotropy of the crust beneath Southeastern China}

The original dataset comes from three-component records obtained by wide-angle seismic profiling conducted in 1990 as part of the Southeastern China Continental Dynamics project aimed at the study of the contact between the Yangtze block and the Cathaysia block. In the frame of this project, the $380-\mathrm{km}$-long profile shown in Fig. 6, with azimuth nearly $\mathrm{N} 30^{\circ} \mathrm{W}$, ran from Fengle Reservoir near Tunxi, Anhui Province, to Dongtou Island, offshore of Wenzhou, Zhejiang Province, crossing several major lithologic boundaries and numerous faults. Five in-line shots, consisting of a hole drilled at a depth of $20 \mathrm{~m}$ and loaded with a charge ranging from 1,200 to $1,800 \mathrm{~kg}$ of explosive, were fired at different sites, Fengle, Xinanjiang, Songyang, Qingtian, and Dongtou, and recorded by 85 portable seismic stations, most of them three-component stations, with spacing of about $3 \mathrm{~km}$ along the recording line. The propagating seismic phases, recorded with an average trace gap of $3 \mathrm{~km}$ at distances from 2 to $240 \mathrm{~km}$ from the shot site, are displayed in Fig. 7 as P-wave record sections at reduced time scale using a common velocity of $6.0 \mathrm{~km} / \mathrm{s}$.

Almost all the P-wave traces of vertical, radial, and transverse ground-motion registered along the profile exhibit a high signal-to-noise ratio. From these record sections, we are able to clearly identify not only the Pg energy arrival refracted above of the crystalline basement but also the Pm-phase reflected from the Moho. The Pn-phase refracted from the Moho can also be recognized even though the amplitudes are very weak as compared with the amplitude of the previous phases. Other P-phases reflected from interfaces between the crystalline basement and the crustmantle discontinuity (events P1, P2, P3, and $\mathrm{P} 4)$ are recognized too. P- and S-wave traveltime interpretations are described in detail elsewhere (Xiong et al. 1993; Zhang et al. 2000, 2005).

From among the shots, three of them fired at Xinanjiang, Songyang, and Qingtian (Fig. 6) were recorded at both directions along direct and reversed profiles and therefore give two-sided record sections (Fig. 7). In the following, we only consider the longest transects for phase correlation: the right side moving away from Xinanjiang and the left sides from Songyang and Qingtian. Because of our 1-D limitation, we choose appropriate distance ranges (less than $80 \mathrm{~km}$ ) for the P-phases detected in the stacked seismograms and their respective travel times. In the computation, the non-negligible free-surface effects were corrected following to Macbeth (2002) and Mario (2003).

We analyze the polarizations of all the crustal P-phases (Pg, P1, .., Pm) from the threecomponent array data using the eigenvalueeigenvector method based on the data covariance matrix (Flinn 1965; Benhama et al. 1988; Jurkevics 1988; Perelberg and Hornbostel 1994). The method is applied with the help of a time variable window whose size depends on the signal frequency; since this frequency is around $5 \mathrm{~Hz}$ that is a period of $0.2 \mathrm{~s}$, we take $0.1,0.2$, and $0.3 \mathrm{~s}$ as widths of the time gates for polarization measurements from the three-component waveforms. The procedure is implemented as follows: On a waveform recorded at a certain offset, we first identify a particular crustal phase like a main energy arrival at a time, and then, using a $0.1 \mathrm{~s}$ time gate and taking a temporal portion of 40 samples, we compute the polarization angle, after which we repeat the calculation employing a 0.2-s time window and 80 samples and again a 0.3 -s time gate and 120 samples; thereby, we have up to three polarization values at the offset of reference. We repeat these operations for other distances, and also for other phases, to obtain offset-dependent polarization angles for all the correlated phases and therefore their respective polarization curves. Figure 8 illustrates the procedure graphically: It shows the radial, transverse, and vertical components of the round motion recorded at $75.87 \mathrm{~km}$ from the shot fired at Fengle; several crustal phases can be observed and the three-time gates used for polarization measurements as well. Examples of polarization curves for two particular phases are plotted together with the polarization curves finally selected.

We thereafter reconstruct (layer by layer) the vertical P-wave velocity, the reflector depths, and the anisotropy parameters for the five tested 
Fig. 8 Upper part A zoomed-in view of the radial $(X)$, transverse $(Y)$, and vertical $(Z)$ components of the ground motion recorded at $75.87 \mathrm{~km}$ from the shot fired at Fengle, which include several crustal P-phases $(\mathrm{P} 1, \ldots, \mathrm{Pm})$ correlated like main energy arrivals at different times. The 0.1 , 0.2 , and $0.3 \mathrm{~s}$ time gates applied on temporal portions of the waveforms for polarization measurements are represented by short horizontal segments. Lower part Offsetdependent polarization angles estimated with the three time gates for two sample phases, P1 and P3, are plotted together with the polarization curves finally selected
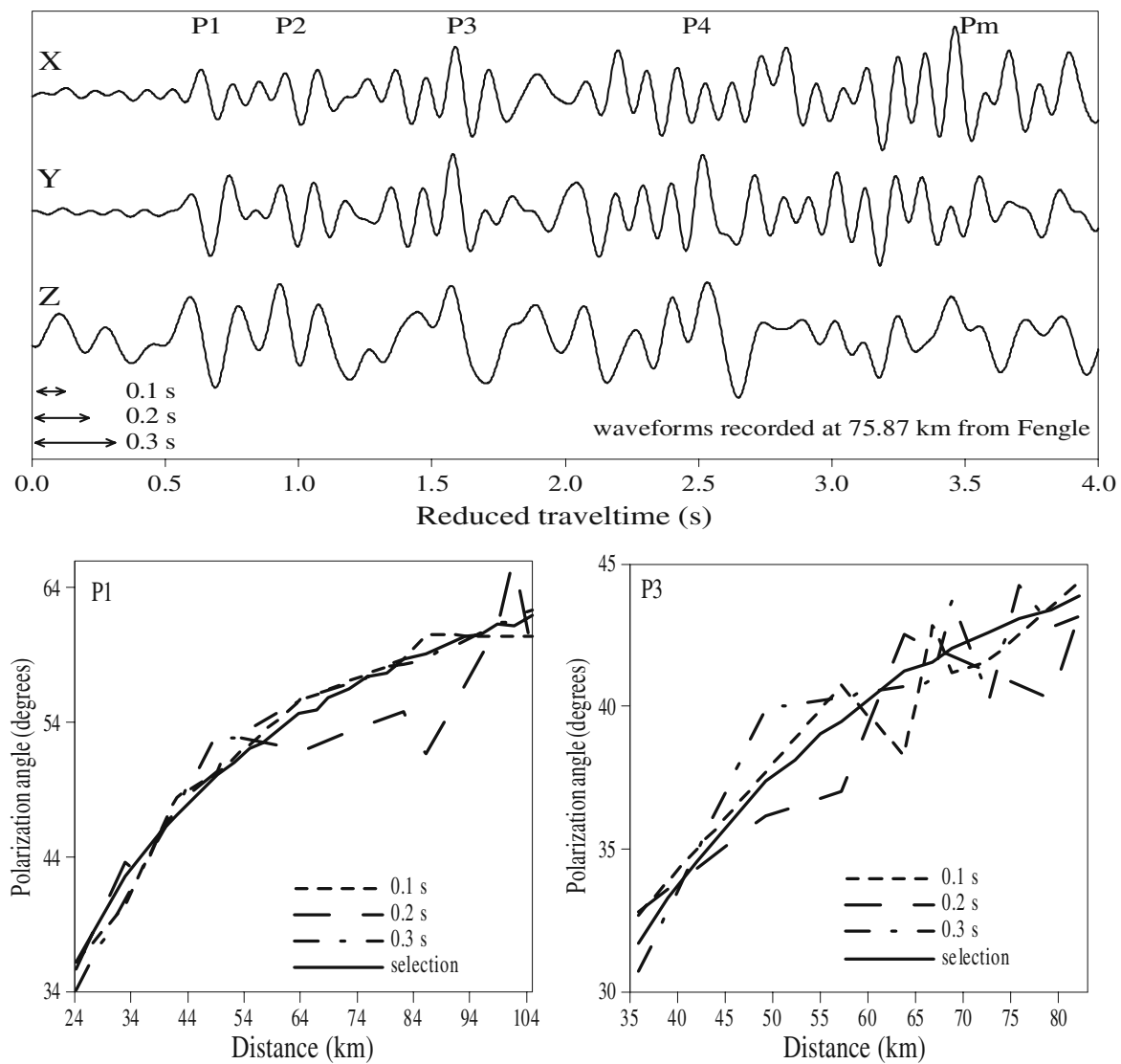

crustal structures, initially by isotropic inversion and after by anisotropic joint inversion of the travel times and polarization data acquired before from the original wide-angle seismic dataset. Then, we make forward computation of travel times and polarization angles using the inversion models obtained by the two methods. Figures 9 and 10 show these last results derived through (isotropic or anisotropic) inversion and forward modeling, together with the times read directly on the seismograms and the polarizations determined from the waveform analysis. In the useful frequency band, we observe wide-angle polarizations dependent on source-receiver distances less than $80 \mathrm{~km}$ (Fig. 10). The comparison makes it clear that the anisotropic model really fits better, as the results determined by anisotropic joint inversion fit nearly the real data better than those determined by isotropic inversion. Figure 11 shows the depth-dependent vertical $\mathrm{P}$-wave velocity $\left(v_{p 0}\right)$ and the Thomsen's anisotropy parameters $(\varepsilon$ and $\delta$ ) for the five tested crustal columns at depths down to $30-35 \mathrm{~km}$. The real travel times that we have picked might contain an undesirable amount of error, which would result in uncertainty of the computed final solution. In order to give a measure of this uncertainty, we acquire new travel times with a perturbation of $5 \%$ and invert again these perturbed data; horizontal error bars in Fig. 11 show graphically the errors so obtained in all cases.

The vertical P-wave velocities found for the shallowest materials are $5.30 \mathrm{~km} / \mathrm{s}$ at Fengle Reservoir, $5.71 \mathrm{~km} / \mathrm{s}$ at Xinanjiang, $5.50 \mathrm{~km} / \mathrm{s}$ at Songyang, $5.72 \mathrm{~km} / \mathrm{s}$ at Qingtian, and $5.55 \mathrm{~km} / \mathrm{s}$ at Dongtou. A good correlation between these seismic velocity values and the geological outcrops is observed: Relatively low velocities coincide with the presence of sedimentary or volcanic materials. At crustal depths ranging from 25 to $35 \mathrm{~km}$, we observe velocity changes at both sides of the Jiangshan-Shaoxing fault, the P-wave velocity 
Fig. 9 Crustal P-phase reflection travel times obtained through either isotropic inversion (blue lines) or anisotropic inversion (red lines) and then forward modeling, which are contrasted with the times read directly on the seismograms (black lines)
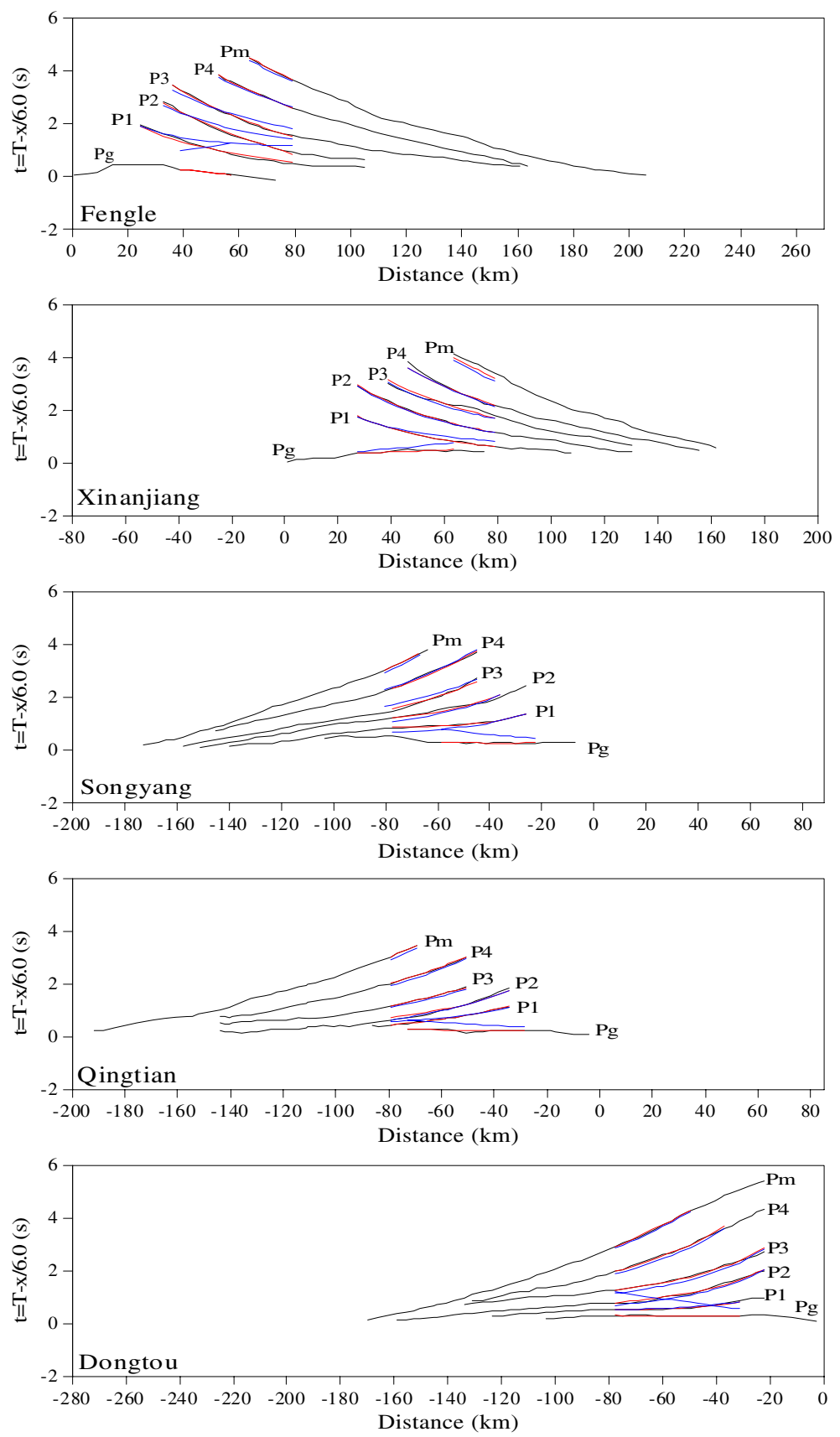

passing from 6.68 to $6.88 \mathrm{~km} / \mathrm{s}$ in the north and from 6.51 to $6.96 \mathrm{~km} / \mathrm{s}$ in the south. These results are similar to those reported by Zhang et al. (2005), although such changes of depth-dependent velocity are not exactly the same because of the different layering. The maximum depth of the crust, the Moho, is about $35 \mathrm{~km}$ at Fengle and $30 \mathrm{~km}$ at Dongtou, thus revealing gradual thinning of the crust from northwest to southeast (offshore), which is a gross structural feature re- 
Fig. 10 Crustal P-phase polarization angles obtained through either isotropic inversion (blue lines) or anisotropic inversion (red lines) and then forward modeling, which are contrasted with the polarizations determined directly from the waveforms (black lines)
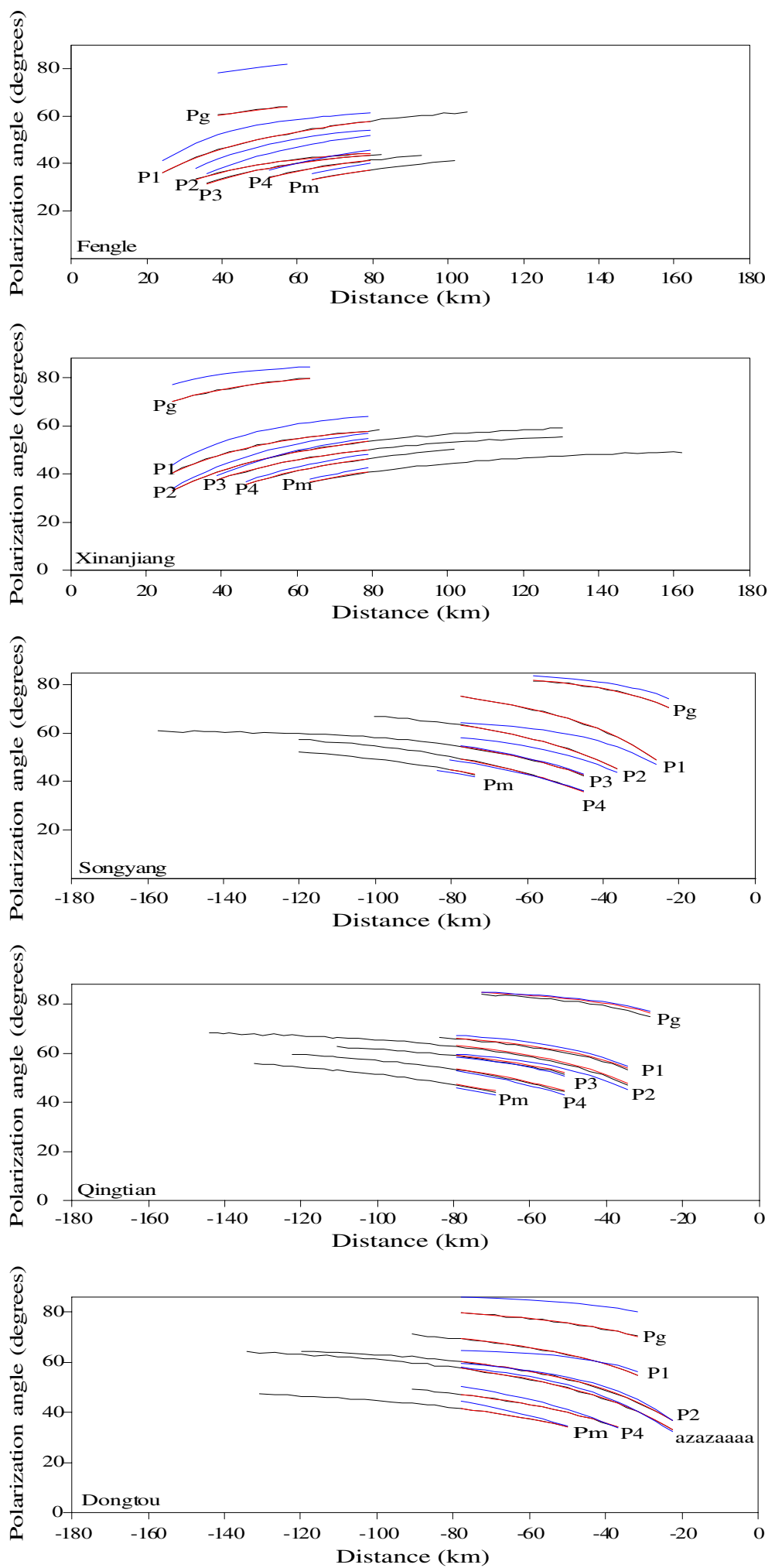
Fig. 11 P-wave velocity $\left(V_{\mathrm{p}}\right)$ and Thomsen anisotropy parameters ( $\varepsilon$ and $\delta$ ) at depths down to $30-35 \mathrm{~km}$ depicting crust models beneath the test sites. Short horizontal segments are error bars
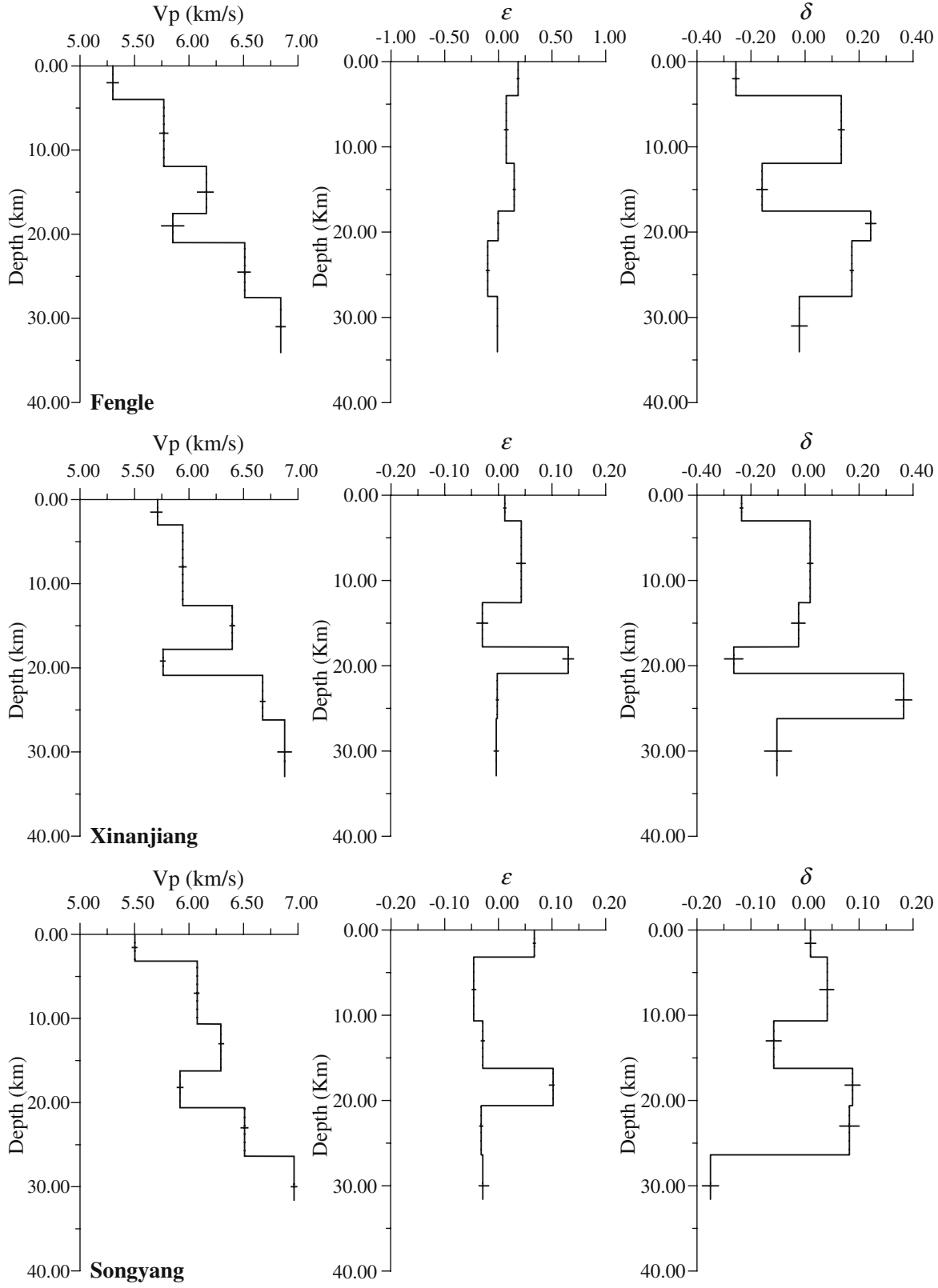

ported by other authors (Xiong et al. 1993; Zhang et al. 2003, 2005).

The anisotropy magnitude under the northwest segment of the profile (at Fengle and Xinanjiang) is different from the existent anisotropy under the southeast transect. The average value of the parameter $\varepsilon$ is 0.061 in the north third of the profile but almost half, 0.038 , in the southern part. Although in a lesser proportion, the average value of the parameter $\delta$ also reveals a change from 0.166 in north direction to 0.145 in south direction. However, whereas the mean value of the anisotropy parameter $\delta$ is practically the same at Fengle and Xinanjiang, 0.164 and 0.168, respectively, it becomes 0.075 at Songyang and beyond, making clear different anisotropy conditions at both sides of the Jiangshan-Shaoxing fault that seems to delimit two distinct tectonic blocks.

Figure 12 displays the fast $\mathrm{P}$-wave direction for different reflectors at crustal-scale together with 
Fig. 11 (continued)

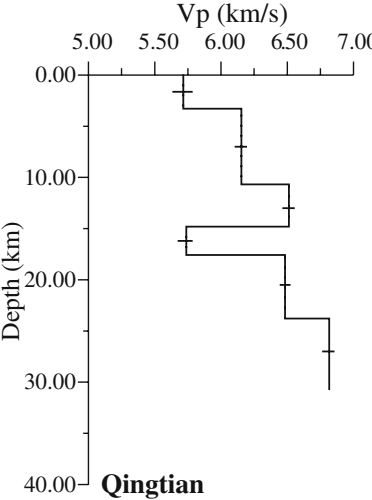

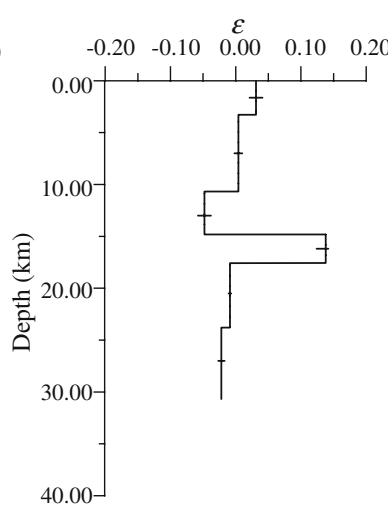

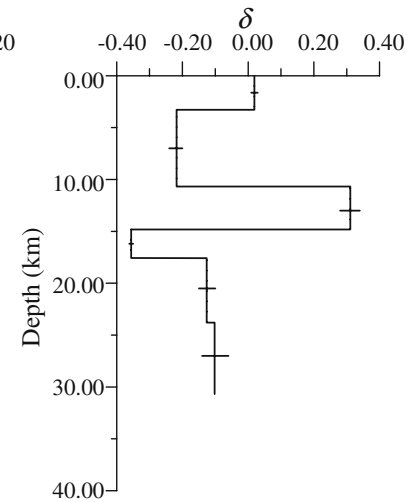

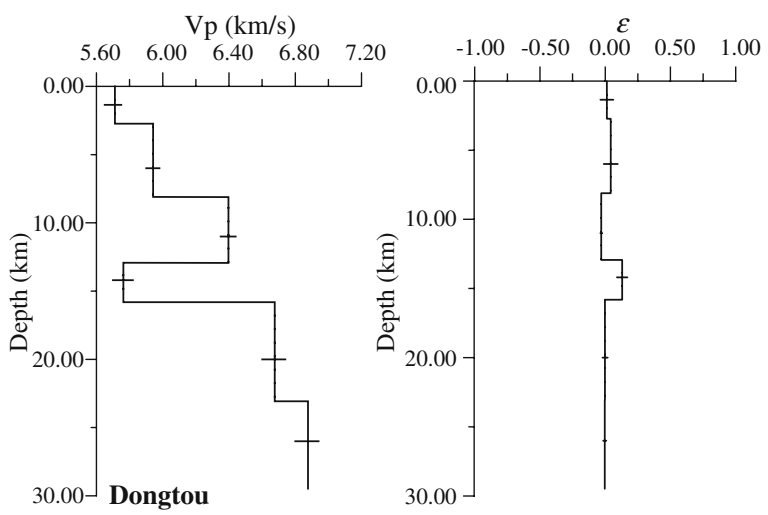

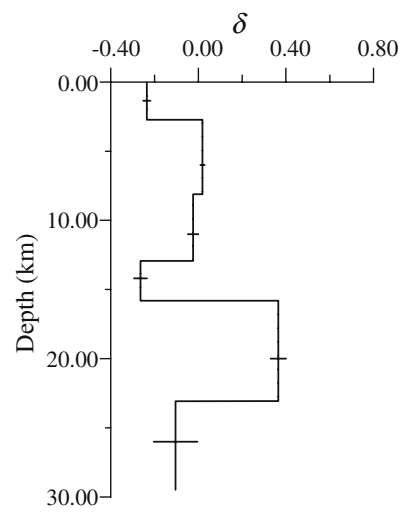

\section{Distance (km)}

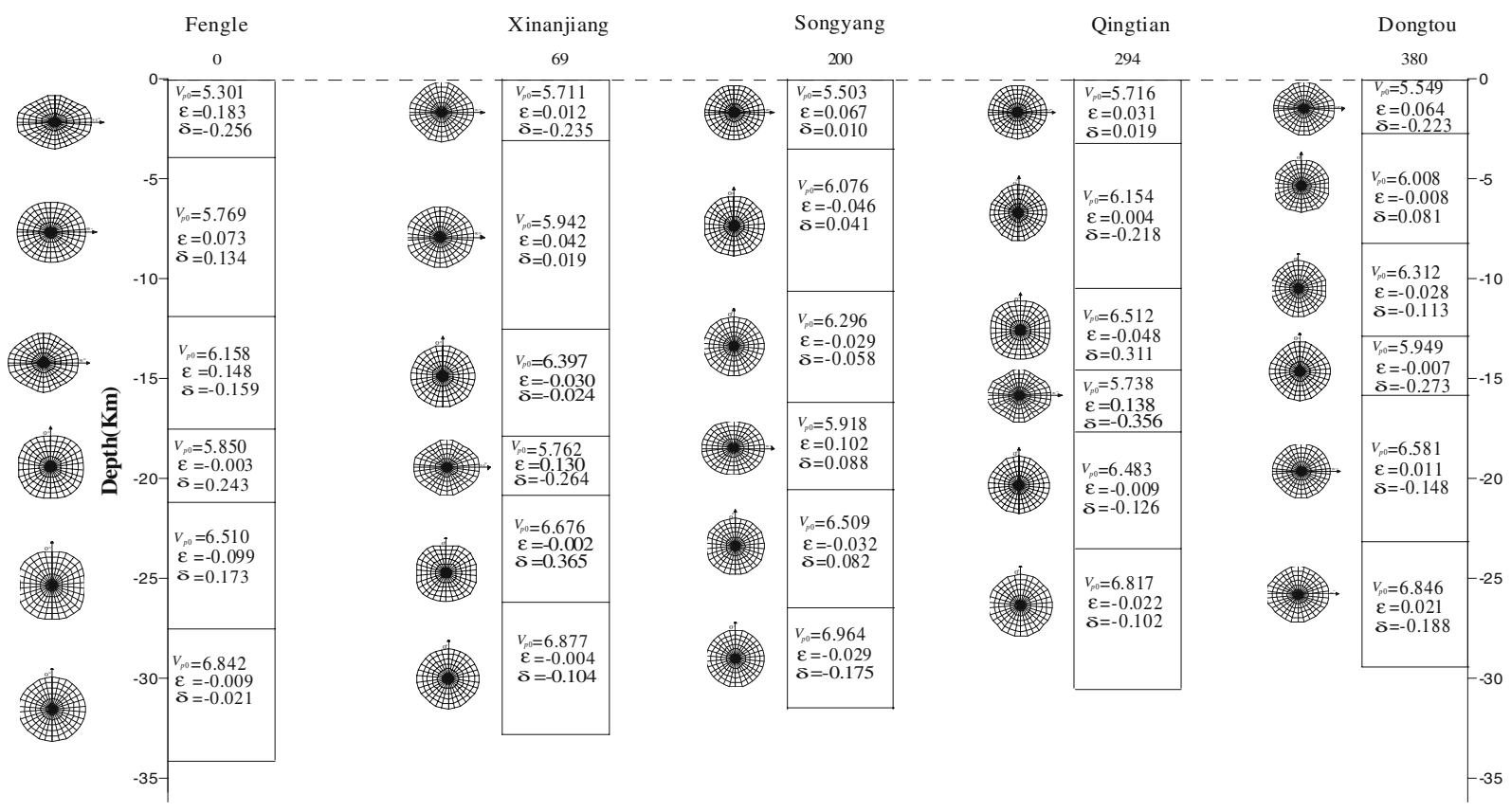

Fig. $12 \mathrm{P}$-wave velocity $\left(V_{\mathrm{po}}\right)$ and Thomsen anisotropy parameters $(\varepsilon$ and $\delta$ ) for the five tested crustal columns. Fast $\mathrm{P}$-wave directions for different reflectors and sites are also given 
the P-wave velocity and anisotropy results for every layer belonging to the investigated crustal sections. It is obvious that the fast $\mathrm{P}$-wave direction is mainly horizontal in the upper crust, but an appreciable difference is found under Songyang, Qingtian, and Dongtou, to the southeast of the Jiangshan-Shaoxing fault, where the fast P-wave direction is clearly vertical. Just this long fault has been recognized as the natural boundary between the Yangtze and Cathaysia blocks from geological, geochemical, and geophysical evidences (Hsu et al. 1988, 1990; Gilder et al. 1993, 1995, 1996; Pei and Hong 1995; Chen and John 1998; Hong et al. 1990, 2002; Zhang et al. 2005, 2008; Zhang and Wang 2007).

\section{Conclusions}

We present an approach that reconstructs the vertical P-wave velocity, the layer thickness, and the Thomsen's parameters for weak anisotropy after obtaining anisotropic stiffness coefficients in VTI media through joint inversion of seismic reflection travel times and polarization angles. The inverse problem is firstly posed in matrix form and then formulated as a system of four algebraic linear equations referred to a layer of the anisotropic elastic solid. The linear working scheme is layer by layer by applying a least-squares method, and the final layer solution is found iteratively minimizing the error expectancy for the physical properties here searched into.

First anisotropic travel-time inversion for anisotropic stiffness coefficients has permitted us to test the method with synthetic data and compare the outputs with the results obtained by joint inversion, these latter revealing a satisfactory fit to the initial earth model, thus supporting the reliability of our joint inversion scheme. Then, we further obtain the layer thickness, P-wave velocity, and Thomsen's parameters because of good indication for anisotropic media.

The joint inversion method is applied to real data acquired from three-component waveforms obtained by wide-angle seismic profiling in Southeastern China. We have done a sequence of 1$\mathrm{D}$ inversions along the entire profile, centered at each of the shot sites. On the basis of the seis- mic anisotropy signature of the regional crust, we interpret the laterally varying anisotropy magnitude and the fast P-wave direction as clear evidences in support of the Jiangshan-Shaoxing fault as the natural boundary between the Yangtze tectonic block and the Cathaysia tectonic block.

Because of the complexity of the formulation for VTI media with weak anisotropy, in this paper, we have tackled the problem of a 1-D (layer cake) earth model. Far from this simplistic model, a more realistic (and interesting) problem is when the earth is fairly close to being layered in dipping interfaces, still more if one is limited to data from an un-reversed profile. Although this case is out of our score in the present paper, we do not renounce to develop a more complex formulation in a further study.

Acknowledgements $\mathrm{We}$ are indebted to all those who supplied us original information for this study. We would like to thank the Institute of Geology and Geophysics, Chinese Academy of Sciences (IGGCAS), the facilities given for data acquisition and the permission to publish this work. We benefited from the valuable comments and guidance of Prof. Zhongjie Zhang. Helpful comments and constructive suggestions from anonymous referees that led to significant improvement of the manuscript are gratefully acknowledged. The Chinese Academy of Sciences and the Chinese National Nature Sciences Foundation supported this research through the projects KXCX2-109, 49825108, and 40304007. The present work takes advantage of the Collaboration Agreement between the Institute of $\mathrm{Ge}$ ology and Geophysics of Beijing, Chinese Academy of Sciences, and the University of Zaragoza, Spain.

\section{References}

Alkhalifah T, Tsvankin I (1995) Velocity analysis for transversely isotropic media. Geophysics 60:1550-1566

Backus GE (1962) Long-wave elastic anisotropy produced by horizontal layering. J Geophys Res 67:4427-4440

Bai Z, Wang C (2004) Tomography research of the Zhefang-Binchuan and Menglian-Malong wide-angle seismic profiles in Yunnan province. Chinese J Geophys 47:257-267

Benhama A, Cliet C, Dubesset M (1988) Study and applications of spatial directional filtering in threecomponent recordings. Geophysical Prospecting 36:591-613

Berryman JG (1979) Long-wave elastic anisotropy in transversely isotropic media. Geophysics 44:896-917

Bishop TN, Bube KP, Cutler RT (1985) Tomographic determination of velocity and depth in laterally varying media. Geophysics 50:903-923 
Byun BS, Corrigan D (1990) Seismic traveltime inversion for transverse isotropy. Geophysics 55:192-200

Chen JF, John BM (1998) Crustal evolution of southeastern China: Nd and $\mathrm{Sr}$ isotropic evidence. Tectonophysics 284:101-133

Crampin S (1986) Anisotropy and transverse isotropy. Geophys Prospect 34:94-99

Eduardo LF, Paul LS (1994) Traveltime compution in transverly istropic media. Geophysics 59:272-281

Flinn EA (1965) Signal analysis using rectilinearity and direction of particle motion. Proc IEEE 12:18741876

Gilder SA, Coe RS, Wu HR, Kuang GD, Zhao XX, Wu Q, Tang XZ (1993) Cretaceous and Tertiary paleomagnetic results from southeast China and their tectonic implications. Earth Planet Sci Lett 117:637-652

Gilder SA, Coe RS, Wu HR, Kuang GD, Zhao XX, Wu Q (1995) Triassic paleomagnetic data from south China and their bearing on the tectonic evolution of the western circum-pacific region. Earth Planet Sci Lett 131:269-287

Gilder SA, Gill J, Coe RS (1996) Isotopic and paleo constraints on the Mesozoic tectonic evolution of south China. J Geophys Res 101:16137-16154

Grechka V, Pech A, Tsvankin I, Han B (2001) Velocity analysis for tilted transversely isotropic media: a physical modelling example. Geophysics 66:904-910

Helbig K (1983) Elliptical anisotropy: its significance and meaning. Geophysics 48:825-832

Helbig K (1984) Transverse isotropy in exploration seismology. Geophys JR Astr Soc 76:79-88

Helbig K, Schoenberg M (1987) Anomalous polarization of elastic waves in transversely isotropic media. J Acoust Soc Am 81:1235-1245

Hong D, Xie X, Zhang J (1990) Isotope geochemistry of granitoids in south China and their metallogeny. Res Geol 48:251-263

Hong D, Xie X, Zhang J (2002) Geological significance of the Hangzhou-Zhuguangshan-Huashan high granite belt. Geol Bull of China 21:348-354

Horne S, Leaney S (2000) Polarization and slowness component inversion for VTI anisotropy. Geophys Prospect 48:779-788

Hsu KJ, Sun S, Li JL, Chen HH, Peng HP, Sengor AMC (1988) Mesozoic overthrust tectonics in south China. Geology 16:418-421

Hsu KJ, Li JL, Chen HH, Wang QC, Sun S, Sengor AMC (1990) Tectonics of South China: key to understanding West Pacific geology. Tectonophysics 183: 9-39

Hu G, William M (1992) Formal inversion of laterally heterogeneous velocity structure from $\mathrm{P}$-wave polarization data. Geophys J Int 110:63-69

Hudson JA (1980) Overall properties of a cracked solid. Math Proc of the Cambridge Philosophical Society 88:371-384

Jurkevics A (1988) Polarization analysis of threecomponent array data. Bull Seism Soc Am 78:17251743

Levin FK (1979) Seismic velocities in transversely isotropic media. Geophysics 44:918-936
Lutter WJ, Nowack RL (1990) Inversion for crustal structure using reflections from the PASSCAL Ouachita experiment. J Geophys Res 95:4633-4646

Macbeth C (2002) Multi-component vsp analysis for applied seismic anisotropy, Elsevier Science Ltd.

Mario R (2003) Analysis of particle motion recorded by three-component seismic stations. Final Report, GEOP 523

Park J, Vernon FL, Lindberg CR (1987) Frequency dependent polarization analysis of high-frequency seismograms. J Geophys Res 92:12664-12674

Pavlis GL, Booker JR (1980) The mixed discrete continuous inverse problem: application to the simultaneous determination of earthquake hypocenters and velocity structure. J Geophys Res 85:4801-4810

Pei R, Hong D (1995) The granites of south China and their metallogeny. Episodes 18:77-82

Perelberg AL, Hornbostel SC (1994) Applications of seismic polarization analysis. Geophysics 59:119_ 130

Postma GW (1955) Wave propagation in a stratified medium. Geophysics 20:780-806

Pullammanappallil SK, Louie JN (1993) Inversion of seismic reflection traveltimes using a nonlinear optimization scheme. Geophysics 58:1607-1620

Pullammanappallil SK, Louie JN (1994) A generalized simulated-annealing optimization for inversion of first-arrival times. Bull Seism Soc Am 84:13971409

Pullammanappallil SK, Louie JN (1997) A combined firstarrival travel time and reflection coherency optimization approach to velocity estimation. Geophys Res Lett 24:511-514

Qin Y, Zhang Z, Li S (2003a) CDP mapping in tilted transversely isotropic (TTI) media, Part I: method and effectiveness. Geophysical Prospecting 51:315-324

Qin Y, Zhang Z, Xu S (2003b) CDP mapping in tilted transversely isotropic (TTI) media, Part II: velocity analysis by combining CDP mapping with a genetic algorithm. Geophysical Prospecting 51:325-332

Rommel BE (1994) Approximate polarization of plane waves in a medium having weak transverse isotropy. Geophysics 59:1605-1612

Samuel HB (1990) Velocity-depth ambiguity of reflection traveltimes. Geophysics 55:266-276

Spencer C, Gubbins D (1980) Travel-time inversion for simultaneous earthquake location and velocity structure determination in laterally varying media. Geophys J R Astron Soc 63:95-116

Thomsen L (1986) Weak elastic anisotropy. Geophysics 51:1954-1966

Tsvankin I (1996) P-wave signatures and notation for transversely isotropic media, an overview. Geophysics 61:467-483

Tsvankin I, Thomsen L (1995) Inversion of reflection traveltimes for transverse isotropy. Geophysics 60: 1095-1107

Vidale JE (1986) Complex polarization analysis of particle motion. Bull Seism Soc Am 76:1393-1405

Xiong S, Lai M, Liu H, Yu K (1993) Lithosphere structure and velocity distribution from Tunxi to Wenzhou. In: 
Li J (ed.) Lithosphere structure and geological evolution of Southeastern China. China Meteorological Press, Beijing

Yang DH, Liu E, Zhang Z, Teng J (2002) Finite-difference modelling in two-dimensional anisotropic media using a flux-corrected transport technique. Geophys J Int $148: 320-328$

Zelt CA, Smith RB (1992) Seismic traveltime inversion for 2-D crustal velocity structure. Geophys J Int 108 : $16-34$

Zhang Z, Wang G, Teng J, Klemperer S (2000) CDP mapping to obtain the fine structure of the crust and upper mantle from seismic sounding data: an example for Southeastern China. Phys Earth Planet Inter 122: 133-146
Zhang Z, Lin G, Chen J, Harris JM, Han L (2003) Inversion for elliptically anisotropic velocity using VSP reflection traveltimes. Geophysical Prospecting 51: 159-166

Zhang Z, Badal J, Li Y, Chen Y, Yang L, Teng J (2005) Crust-upper mantle seismic velocity structure across southeastern China. Tectonophysics 395:137-157

Zhang Z, Wang Y (2007) Crustal structure and contact relationship revealed from deep seismic sounding data in South China. Phys Earth Planet Inter doi:10.1016/j.pepi.2007.08.005

Zhang Z, Zhang X, Badal J (2008) Composition of the crust beneath Southeasthern China by an integrated geophysical dataset. J Geophys Res 113, B04417, doi:101029/20006JB004503 